\title{
Anterior Forebrain Neurons Develop Selectivity by an Intermediate Stage of Birdsong Learning
}

\author{
Michele M. Solis and Allison J. Doupe \\ Keck Center for Integrative Neuroscience and Neuroscience Graduate Program, Departments of Physiology and \\ Psychiatry, University of California, San Francisco, San Francisco, California 94143-0444
}

Auditory neurons of the anterior forebrain (AF) in adult zebra finches are highly selective for the bird's own song (BOS): they respond more to BOS than to songs of other zebra finches (conspecifics) and to BOS played in reverse. In contrast, juvenile AF neurons are not selective at $30 \mathrm{~d}$ of age, responding equally well to all song stimuli. Both BOS and tutor song experience are required by juveniles for normal song learning and may produce the selective properties of adult neurons. Because such selectivity could subserve song learning, it is important to determine when it arises. Birds were therefore studied at an intermediate stage of learning, after substantial experience of both tutor song and their own developing (plastic) song.

Extracellular single neuron recordings in 60-d-old zebra finches revealed that AF neurons had significant song and order selectivity for both tutor song and BOS (the bird's plastic song). The degree of BOS selectivity was less than that found in adults, as indicated in part by $60 \mathrm{~d}$ neurons that were sensitive to the local order within syllables but not yet to the global order of syllables within a song. When responses to BOS and tutor song were compared, most neurons preferred BOS, some preferred tutor song, and others responded equally to both stimuli. The latter type of neuron was not simply immature, because many of these neurons responded significantly more to BOS and tutor song than to conspecific and reverse songs.

The selectivity of AF neurons at $60 \mathrm{~d}$ is markedly different from the unselective properties of neurons at $30 \mathrm{~d}$ and may function in vocal learning at this stage. Moreover, the selectivity for both BOS and tutor song raises the possibility that both aspects of the birds' sensory experience during learning are reflected in properties of AF neurons.

Key words: auditory selectivity; song selectivity; order selectivity; temporal processing; experience-dependent plasticity; zebra finch; song learning; LMAN; Area $X$
Auditory neurons of the songbird forebrain are some of the most complex sensory neurons known, responding best to song stimuli (Margoliash, 1983; Doupe and Konishi, 1991). Other examples of neuronal selectivity for species-specific vocalizations have been found in moustache bat (Suga et al., 1978), rhesus monkey (Rauschecker et al., 1995), and marmoset (Wang et al., 1995). Of these, only songbird neurons have been shown to acquire their selectivity during learning (Volman, 1993; Doupe 1997). In adult birds, the neurons of the anterior forebrain (AF) are highly selective for the bird's own song (BOS), preferring it to the songs of other zebra finches (conspecifics) and to BOS played in reverse. In contrast, AF neurons of 30-d-old juveniles lack selectivity, responding equally well to all song stimuli (Doupe, 1997) (Fig. 1A). Because auditory experience of both BOS and tutor song are required for normal song development, these songs may shape AF neuron selectivity. Furthermore, selectivity may play a role in song learning, if present in a bird in the process of vocal development. Determining when selective neurons emerge will inform hypotheses about the purpose of selectivity, as well as AF function, during song learning.

Received March 31, 1997; revised May 27, 1997; accepted May 30, 1997.

This work was supported by the Lucille P. Markey Charitable Trust, the Klingenstein Fund, the McKnight Foundation, the Searle Scholars Program, the Sloan Foundation, National Institutes of Health Grant MH55987 (A.J.D.), and a National Science Foundation graduate fellowship (M.M.S.). We thank Frédéric Theunissen for invaluable technical help and Michael Brainard, Mark Konishi, and Michael Lewicki for insightful comments on this manuscript.

Correspondence should be addressed to Michele M. Solis, Department of Physiology, Box 0444, University of California, San Francisco, 513 Parnassus Avenue, San Francisco, CA 94143-0444.

Copyright (C) 1997 Society for Neuroscience $0270-6474 / 97 / 176447-16 \$ 05.00 / 0$
Songbirds learn their songs in two phases, which overlap in zebra finches (Fig. 1B). During the sensory phase, a young bird listens to and memorizes the tutor song; this stored memory is often called the "template." Later, during the sensorimotor phase, the juvenile bird begins to vocalize, producing "plastic song." Plastic song is soft and rambling, has poor syllable morphology, and lacks a stereotyped syllable order. The bird uses auditory feedback to gradually match its own immature vocalizations to the memorized tutor song. In this way the plastic song is modified until the bird produces a mature "crystallized" song, which is often a good copy of its tutor song.

Deafening birds in either the sensory or sensorimotor phase impairs learning (Konishi, 1965; Price, 1979), demonstrating the importance of auditory experience to song development. Specifically, birds deafened during the sensory phase cannot memorize their tutor song and hence develop an abnormal song. Birds deafened during the sensorimotor phase cannot compare their own vocalizations to the tutor template, which also results in an abnormal song.

The AF is a subset of the specialized nuclei unique to songbirds, all of which are likely locations for neuronal changes necessary for song learning and production (Fig. 1C). Composed of Area X (X), the medial nucleus of the dorsolateral thalamus (DLM), and the lateral magnocellular nucleus of the anterior neostriatum (LMAN), the AF is required for normal song development (Bottjer et al., 1984; Sohrabji et al., 1990; Scharff and Nottebohm, 1991), perhaps processing important auditory information during learning. A separate motor pathway for song includes $\mathrm{HVc}$ (this acronym is used as the proper name, as 
A
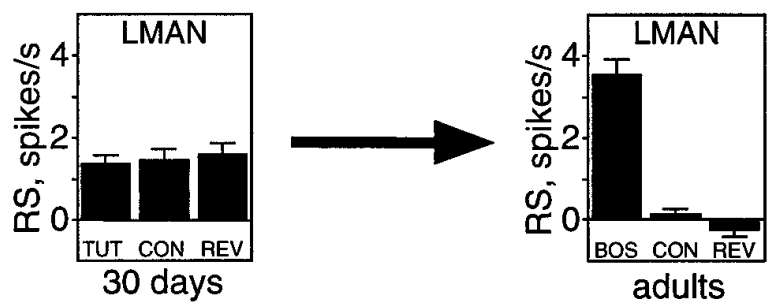

B

\section{sensory phase}

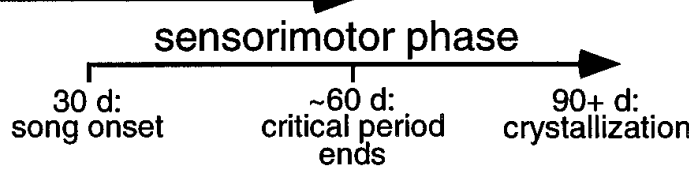

C

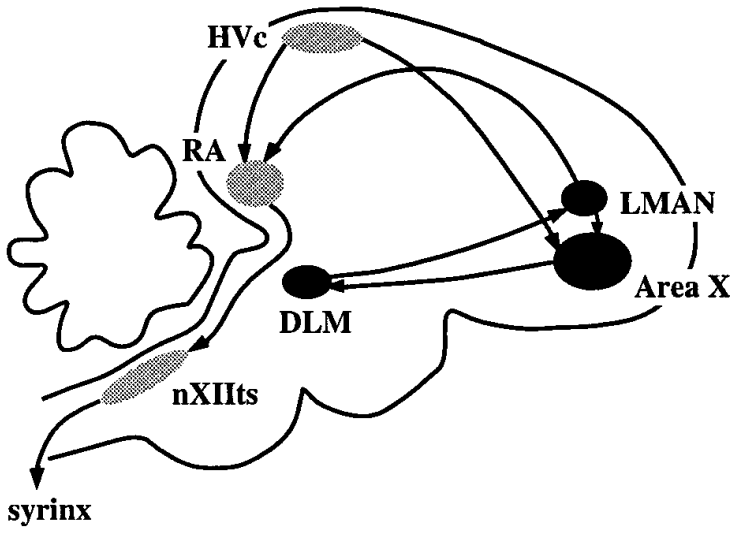

Figure 1. A, LMAN neurons become song and order selective between $30 \mathrm{~d}$ and adulthood. At $30 \mathrm{~d}$ neurons have equal response strengths $(R S)$ to tutor song $(T U T)$, conspecific song $(C O N)$, and tutor reverse $(R E V)$, whereas in adulthood, BOS elicits greater RS than CON or BOS reverse $(R E V)$ (data from Doupe, 1997). B, Time course of zebra finch song learning. Juveniles learn their song in two overlapping phases; the sensory phase ends at $\sim 60 \mathrm{~d}$, and the sensorimotor phase begins at $\sim 30 \mathrm{~d}$ and continues to adulthood $(90+$ d). $C$, The anatomy of the song system is illustrated, with the nuclei of the anterior forebrain in black and those of the motor pathway in gray.

proposed by Fortune and Margoliash, 1995), the robust nucleus of the archistriatum (RA), and the tracheosyringeal portion of the hypoglossal nucleus (nXIIts); nXIIts contains the motor neurons innervating the muscles of the syrinx, the avian vocal organ. This motor pathway is necessary for normal song production throughout life (Nottebohm et al., 1976) and might be influenced by its input from the AF.

To address whether selectivity is present in the AF of a learning bird, individual LMAN and $\mathrm{X}$ neurons were recorded in 60-d-old zebra finches. At this age, birds are at an intermediate stage of song development; the sensory phase is ending, and the sensorimotor phase is under way (Fig. 1B). These birds have probably memorized the tutor song and have been singing plastic song for $\sim 1$ month (Immelmann, 1969; Eales, 1985; Böhner, 1990). In this study both tutor song and BOS (in this case, plastic song) were among the stimuli used to characterize the selectivity of AF neurons, thus permitting the identification of neurons tuned by either BOS or tutor song experience.

\section{MATERIALS AND METHODS}

Animals. Experiments used male zebra finches (Taeniopygia guttata) of $\sim 60 \mathrm{~d}$ of age (range, $55-65 \mathrm{~d}$ ). Birds were raised in individual cages with their parents and siblings from the same clutch. Juveniles learn from the tutor sharing a cage with them, even when other birds are within earshot or sight (Immelmann, 1969; Eales, 1987; Williams, 1990). Although juveniles could hear songs of other conspecifics in the colony, they were visually isolated from them with opaque dividers placed between cages. Visually isolating juveniles from a tutor interferes with learning (Eales, 1989). Thus, keeping juveniles in the same cage as their tutor, combined with visually isolating them from nearby conspecifics, should restrict their learning to the tutor in their cage.

Song recording. One to $2 \mathrm{~d}$ before the experiment, the juvenile's plastic song and its tutor song were recorded, digitized, and entered into a Sparc IPX computer at approximately the same intensity level (software by Larry Proctor and Michael Lewicki, California Institute of Technology). Because of the variable quality of plastic song, the song chosen as BOS was the song most frequently produced. This was decided subjectively, based on listening to many song renditions ( $>25$ songs in most cases). For some experiments, two or three versions of plastic song were used as stimuli. Neurons either responded equally well to all plastic song versions or responded more to the version most frequently produced (see Results).

Surgery. Two days before the experiment, birds were anesthetized with Equithesin $(2 \mathrm{ml} / \mathrm{kg}$, i.m.; $0.85 \mathrm{gm}$ of chloral hydrate, $0.21 \mathrm{gm}$ of pentobarbital, $0.42 \mathrm{gm}$ of $\mathrm{MgSO}_{4}, 2.2 \mathrm{ml}$ of $100 \%$ ethanol, and $8.6 \mathrm{ml}$ of propylene glycol to a total volume of $20 \mathrm{ml}$ with water) and placed in a stereotaxic head holder (Herb Adams, Central Engineering, California Institute of Technology). Using stereotaxic coordinates, locations of song nuclei were marked on the skull, relative to the bifurcation of the midsagittal sinus. A stainless steel post was fixed to the skull over the midsagittal sinus with dental cement (Dentsply, Milford, DE).

On the day of the experiment, the bird was anesthetized with a $20 \%$ solution of urethane $(5 \mathrm{ml} / \mathrm{kg}$, i.m.; Sigma, St. Louis, MO; delivered in three injections at $30 \mathrm{~min}$ intervals). The bird was positioned into the stereotaxic apparatus, and its head was immobilized by fixing the head post to a bar overhead. Body temperature was maintained with a temperature controller (FHC, Brunswick, ME). A parylene-coated tungsten electrode (A-M Systems, Everett, WA) with resistance of 1-2 M $\Omega$ was positioned over the mark designating nucleus location. A craniotomy was performed around the area, the dura was opened, and the electrode was lowered into the brain with a microdrive (Fine Science Tools, Foster City, CA). The animal was then placed into a double-walled anechoic sound-attenuated chamber (Acoustic Systems, Austin, TX) where acoustic stimuli were presented in free field conditions by a speaker $25 \mathrm{~cm}$ away. The frequency response measured at the bird's location inside the chamber was flat $( \pm 5.0 \mathrm{~dB})$ between $500 \mathrm{~Hz}$ and $8 \mathrm{kHz}$.

Stimuli. The stimuli presented included the plastic song of the experimental bird (BOS), the song of its tutor, the songs of other adult and juvenile $(60 \mathrm{~d})$ zebra finches (conspecifics), the songs of other species of estrildid finches (heterospecifics), broad band noise bursts, and tone bursts. Although HVc neurons (input nucleus to the AF) are relatively insensitive to intensity differences (Margoliash and Fortune, 1992), stimuli were presented at equivalent intensities. The mean \pm SEM peak intensity of song stimuli was $67.6 \pm 0.43 \mathrm{~dB}$ sound pressure level (range, $62-73 \mathrm{~dB}$; measured with a Brüel and Kjær 2209 sound level meter and 4134 condenser microphone). These stimuli were presented in an interleaved fashion, with 6-8 sec between them to reduce the possibility of habituating or entraining the neurons. In some experiments, stimuli were presented in interleaved, random order. An effort was made to present each neuron with 15-20 trials of BOS, reverse BOS (song is completely reversed), reverse order BOS (temporal order of each syllable remains intact, but the sequence of syllables within the song is reversed), tutor song, reverse tutor song, reverse order tutor song, at least two different adult conspecific songs, at least 2 different juvenile conspecific songs, at least 2 different heterospecific songs, broad band noise bursts, and tone bursts; however, some neurons were lost before complete characterization.

Electrophysiology. Extracellular neuronal signals were amplified and filtered between $300 \mathrm{~Hz}$ and $10 \mathrm{KHz}$ (A-M Systems). Search stimuli used to locate auditory neurons included BOS, tutor song, conspecific song, heterospecific song, broad band noise bursts, and tone bursts. Most single neurons were isolated with a window discriminator (Physiology Shop, University of California, San Francisco); others were obtained from recorded waveforms using spike-sorting software (Lewicki, 1994). Responses to acoustic stimuli were collected and analyzed by a Sparc IPX 
computer using software developed by Michael Lewicki and Larry Proctor (California Institute of Technology) and Frédéric Theunissen (University of California, San Francisco). Data collected for each stimulus were displayed as raster patterns and summed peristimulus time histograms (30 msec bin width) of 10-20 stimulus presentations. Electrolytic lesions were made at selected locations to enable reconstruction of recording sites after the experiment.

At the end of an experiment, animals were deeply anesthetized with Metofane (Pitman-Moore, Mundelein, IL) and intracardially perfused with $0.9 \%$ saline, followed by $3.7 \%$ formalin in $0.025 \mathrm{M}$ phosphate buffer. Brains were postfixed and cut into $40 \mu \mathrm{m}$ sections with a freezing microtome. Sections were stained with cresyl violet, and electrode tracks and lesions were located. Only neurons confirmed histologically to be in LMAN or X were used. The specific location of a neuron within each nucleus was also documented.

Data analysis. Neuronal responses to a stimulus were quantified for the period during which the stimulus was presented, offset by an estimate of the latency of the response. The latency for each neuron was usually measured by viewing its response to a broad band noise or tone burst as a summed peristimulus time histogram with a bin width of $5 \mathrm{msec}$. Latency was defined as the onset of the first two consecutive bins after stimulus onset in which the number of spikes per bin was at least twice the mean number of spikes per bin before stimulus onset. Because many LMAN neurons failed to respond to broad band noise or tone bursts, it was often not possible to measure latency in this way. For these cases, the latency of another cell within the same nucleus of the same experimental bird was assigned. If there was none, then a default latency slightly longer than the latency characteristic of adult LMAN neurons was used (65 $\mathrm{msec})$.

To be considered auditory and included for analysis, a neuron had to have an average firing rate during at least one stimulus that was significantly different ( $p<0.05$, paired $t$ test) from its average spontaneous rate. The average spontaneous rate was the mean firing rate of two periods during each trial: $2 \mathrm{sec}$ preceding stimulus onset and 2-3 sec beginning $1 \mathrm{sec}$ after the end of the stimulus. For each neuron, the response strength (RS) to a stimulus was calculated by subtracting the spontaneous rate from the firing rate during the stimulus. RS was measured for each trial and then averaged across trials to get a mean RS to the stimulus, expressed in spikes per second. Data from different stimuli, but of the same stimulus type, were also averaged in this way to obtain a value for the RS of a neuron to a particular stimulus type (e.g., individual RS values for each trial to two different adult conspecific songs were averaged together to give a mean RS value for adult conspecific song). A mean RS for each stimulus type for an entire nucleus was also calculated from all LMAN or X neuron responses.

The selectivity of an individual neuron for one stimulus (A) over another stimulus (B) was described with a $d^{\prime}$ value (Green and Swets, 1966; Tolhurst et al., 1983) and a selectivity index (Volman, 1996; Doupe, 1997). Previously used measures of selectivity using ratios $\left[R S_{\mathrm{A}} / R S_{\mathrm{B}}\right.$ or $\log \left(R S_{\mathrm{A}} / R S_{\mathrm{B}}\right)$; Margoliash, 1986; Volman, 1993] were not appropriate for this study because of the frequency of inhibitory responses in LMAN. Instead, the preference of a neuron for stimulus A over stimulus B was described with the metric $d^{\prime}$ such that:

$$
d_{A-B}^{\prime}=\frac{\left(\overline{R S_{\mathrm{A}}}-\overline{R S_{\mathrm{B}}}\right)}{\sqrt{\sigma_{\mathrm{A}}^{2}+\sigma_{\mathrm{B}}^{2}}},
$$

where $\overline{R S_{A}}$ and $\overline{R S_{B}}$ are the mean RS to stimulus $\mathrm{A}$ and $\mathrm{B}$, respectively, and $\sigma^{2}$ is the variance of each mean RS. If $d^{\prime}{ }_{\mathrm{A}}-\mathrm{B}$ is positive, then stimulus $\mathrm{A}$ elicited a greater response; if it is negative, then stimulus $\mathrm{B}$ elicited a greater response. Values of $d^{\prime}{ }_{\mathrm{A}-\mathrm{B}}$ of $\sim 0$ indicate no difference in the responses evoked by $\mathrm{A}$ and $\mathrm{B}$. This $d^{\prime}$ value has an advantage over ratios of mean RS, because the difference between two means is weighted by the variance of their distributions. The $d^{\prime}$ value distinguishes between two means that come from largely overlapping distributions and those that do not and is thus a measure of discriminability between the two stimuli given the two responses. Another advantage of $d^{\prime}$ is its insensitivity to the sample size of each distribution: the difference between the means of the two distributions is normalized by their SD instead of by their SE (as is done for the Student's $t$ test, rendering it highly dependent on sample size). A $d^{\prime}$ value was only calculated for those neurons with significant responses to at least one of the two stimuli compared $(p<$ 0.05 for a paired $t$ test between the response during the stimulus and the spontaneous rate).

A disadvantage of the $d^{\prime}$ value is that it does not convey the magnitude of the difference between the mean RS values to two stimuli ( $d^{\prime}$ normalizes this difference by $1 \mathrm{SD}$, which differs for each pair of means compared). Thus, the difference between mean RS to stimulus A and stimulus B was also expressed using a selectivity index (SI):

$$
\frac{\overline{R S_{\mathrm{A}}}}{\left(\overline{R S_{\mathrm{A}}}+\overline{R S_{\mathrm{B}}}\right)} .
$$

Neurons preferring stimulus A over B have SI values near 1; neurons preferring stimulus B to A have values near 0 , and those with no preference have values of $\sim 0.5$. In general, there was good correspondence between $d^{\prime}$ and SI measures.

A $\left|d^{\prime}\right|$ value of 0.5 was chosen as the criterion for a selective neuron. Cells with a $\left|d^{\prime}\right|$ value of $\geq 0.5$ usually had a mean RS to the preferred stimulus that was at least twice as great as that to a nonpreferred stimulus, as measured by SI (see Fig. $4 B$ ). In addition, a $\left|d^{\prime}\right|$ value of 0.5 characterizes responses to two stimuli that are significantly different from each other by a paired $t$ test $(p=0.031)$ when 20 trials of each stimulus are compared. A previous study also considered an individual cell to be selective when it had significantly different responses to two test stimuli $(p<0.05$, paired $t$ test; Lewicki and Arthur, 1996). In the current study, a $d^{\prime}{ }_{\mathrm{A}}-\mathrm{B}$ value of $\geq 0.5$ indicates a neuron selective for stimulus A over $\mathrm{B}$. Likewise, $d_{\mathrm{A}-\mathrm{B}}^{\prime}$ values of -0.5 or less reflect a selectivity for stimulus B over A.

Normalizing spike counts by the length of song stimulus $(\sim 2 \mathrm{sec})$ to obtain the firing rate during a stimulus did not underestimate $d^{\prime}$ values. For a subset of neurons (12 from LMAN and 7 from X, from three birds), peak RS values during a stimulus were determined using a series of sliding windows, the size of which ranged from 10 to $2000 \mathrm{msec}$. For each window size, $d^{\prime}$ values were calculated using the corresponding peak RS values. In general, $d^{\prime}$ values were smallest for short windows, rose with increasing window length, and reached a plateau for windows of 200-500 msec duration and above. Thus $d^{\prime}$ values calculated with RS normalized by the length of a song also gave maximum $d^{\prime}$ values (data not shown).

Cluster analysis. A Monte Carlo analysis was used to determine

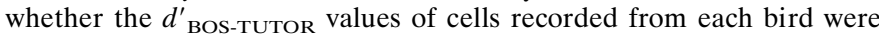
more clustered than expected by chance. To do this, the variance of the $d^{\prime}{ }_{\text {BOS-TUTOR }}$ values obtained from each bird was compared with the distribution of variances that resulted from random draws of all $d^{\prime}{ }_{\text {BOS }}$ TUTOR values from all experiments. This distribution was determined from 1000 Monte Carlo simulations, which randomly selected $n d^{\prime}{ }_{\text {во }}$ TUTOR values from the pool of $d^{\prime}$ BOS-TUTOR values, where $n$ equals the number of cells recorded in each bird. The median of this simulated distribution of variances was then compared with the variance from each experiment. If the experimental variance was significantly less than the median of the simulated distribution (one-sample test, $p<0.05$ ), then it was considered "clustered"; otherwise, the experimental variance was marked "unclustered." A sign test determined whether the frequency of clustered birds was greater than expected by chance. This procedure was completed for $d^{\prime}$ воs-TUTOR values from LMAN alone, $\mathrm{X}$ alone, and both nuclei together.

To determine whether clustered values were attributable to the particular stimulus conditions or duration of an experiment, ratios of stimulus intensity and duration were calculated and correlated to mean $\mathrm{SI}_{\text {BOS-TUTOR }}$ of each bird [specifically, peak BOS intensity/(peak BOS intensity + peak tutor intensity), mean BOS intensity/(mean BOS intensity + mean tutor intensity), and BOS duration/(BOS duration + tutor duration)].

Song analysis. Once electrophysiology experiments were completed, the BOS and tutor song stimuli themselves were analyzed. Song is composed of syllables, which are continuous acoustical signals, 10-200 msec in duration, separated from other syllables by a fall in amplitude to near zero or by brief silent intervals. Syllables themselves are made of smaller continuous signals (without abrupt frequency transitions) called "notes," which give a syllable its morphology. A repeated sequence of syllables is a "motif." A song "bout" consists of introductory notes followed by one or more motifs (for detailed song descriptions, see Price, 1979; Sossinka and Böhner, 1980). Two subjective tests were conducted on the songs: a similarity test and a stereotypy test (Sohrabji et al., 1990; Williams, 1990). For each test, observers familiar with zebra finch song both listened to songs and looked at accompanying sonograms and oscillograms to decide on a score for each experimental animal. Observers were blind to the selective properties of neurons already obtained from each bird. In the similarity test, the similarity of the plastic song to 
the tutor song was compared. Observers were instructed to consider similarities in syllable morphology, syllable order, syllable and motif duration, and rhythm. Each experimental bird's plastic song was scored on a scale of 1-5 according to its similarity to the tutor song. On this scale, a score of 1 described a plastic song that did not at all resemble the tutor song, either in form (syllable morphology) or timing (syllable sequence, duration of syllables, intervals, motifs, or song bouts); 2 referred to a song resembling the tutor in either form or timing; 3 described a song with similarities in both categories but also retaining substantial differences from the tutor song; 4 described a song that shared all or nearly all the elements with the tutor but still exhibited the poor frequency control characteristic of juveniles; and 5 referred to a song that was a good copy of the tutor.

In the stereotypy test, the stereotypy of a plastic song was judged, based on multiple renditions of the bird's plastic song (10 songs analyzed per bird, except in three cases). Observers were instructed to decide whether consistent syllable morphologies, syllable sequences, durations, and motif structures were present in the different renditions of plastic song and to score songs according to the consistency observed. Observers were told to let the frequency of particular syllable sequences predominate in their scoring and to use the consistency of other qualities (details of syllable morphology, durations of syllables, intervals, motifs, or song bouts) to resolve borderline cases. A stereotypy score on a scale of 1-5 was given to each set of plastic songs: a score of 1 was given to a set of plastic songs in which no syllable sequences were repeated across different song samples (i.e., not at all stereotyped); 2 referred to a set for which a particular syllable sequence was repeated in some, but not most, song renditions; 3 described a set for which particular syllable sequences were repeated in all or almost all renditions, but the location of these sequences within a song could vary between songs, and the other syllables of a song could vary in identity or sequence between renditions; 4 was given to a set of songs for which all song elements and sequences were shared in most renditions, with some variation in motif or song duration across songs; and 5 described a set of songs for which all samples consisted of the same syllable sequences, with little variation in song and motif durations (i.e., highly stereotyped).

To control for slight differences in scoring between observers, each score was normalized by the mean score given by that observer, which resulted in a range of normalized scores between 0.3 and 1.9 . Normalized scores from eight observers were then averaged to produce a final similarity score and a final stereotypy score for each experimental bird. Thus, a score of 0.3 corresponds to a song that did not resemble the tutor song or that was not at all stereotyped, and a score of 1.9 corresponds to a song that strongly resembled the tutor song or that was highly stereotyped (e.g., if an observer scored a song as 5, but that observer's average score for all songs was 2.6, then the normalized score for the song would be $5 / 2.6=1.9$ ).

\section{RESULTS}

\section{Selectivity of LMAN neurons at $60 \mathrm{~d}$}

Analysis of 61 LMAN neurons from 16 birds revealed that by $60 \mathrm{~d}$, these neurons were song and order selective for BOS (at this age, plastic song) and tutor song. A song selective neuron responds more to BOS and/or tutor song than to other song stimuli; in this study, these other song stimuli included adult and juvenile (60 d) conspecific songs and heterospecific songs. An example of a $60 \mathrm{~d}$ song selective neuron is shown in Figure $2 A$; although this neuron responded well to both BOS and tutor song, it responded less to an adult conspecific song. Song selectivity was a general feature of LMAN neurons; on average, BOS and tutor song evoked significantly greater responses than other stimulus types (Fig. 2B) (paired $t$ tests, $p<0.0001$ for BOS-adult conspecifics, $n=58$; BOS-juvenile conspecifics, $n=32$; BOS-heterospecifics, $n=60$; and tutor-heterospecifics, $n=60 ; p<0.0011$ for tutoradult conspecifics, $n=58$ ). The song selectivity of individual LMAN neurons is illustrated with scatter plots in which the mean RS to BOS (Fig. 2C) or tutor song (Fig. 2D) of each cell is plotted against its mean RS to adult conspecific song. Many points lie below the diagonal lines, indicating those neurons with stronger responses to BOS or tutor song than to adult conspecific songs. The percentage of song selective LMAN cells (i.e., $d^{\prime}{ }_{\text {BOS-ADULT }}$
CON $\geq 0.5$ and/or $d^{\prime}{ }_{\text {TUTOR-ADULT CON }} \geq 0.5$; see Materials and Methods) in each selectivity category is listed in Table 1.

LMAN neurons had also developed order selectivity by $60 \mathrm{~d}$. An order selective neuron responds more to BOS and/or tutor song than when these songs are completely reversed. In these reverse stimuli, the song is entirely backward, so that both the order of syllables and of the elements within them are reversed. An order selective LMAN neuron is shown in Figure $3 A$, with its strong response to BOS (first panel) significantly reduced on reversing BOS (BOS rev, second panel). On average, LMAN was order selective; the mean RS of all LMAN neurons to forward BOS and tutor song stimuli was significantly greater than that to the corresponding reverse stimuli (Fig. 3B) (paired $t$ test, $p<0.0001$ for BOS-reverse BOS; $n=55$; $p<0.0023$ for tutor-reverse tutor, $n=$ 50). The order selectivity of individual LMAN units is shown in scatter plots in which the mean RS to BOS (Fig. $3 C$ ) or tutor song (Fig. $3 D$ ) of each cell is plotted against its mean $\mathrm{RS}$ to the corresponding reverse stimulus. Many cells responded more to forward than to reverse stimuli and thus fall below the diagonal line. Of the LMAN neurons tested, $81 \%$ were selective for forward over reverse stimuli $\left(d^{\prime}{ }_{\text {BOS-REV }} \geq 0.5\right.$ and/or $d^{\prime}{ }_{\text {TUTOR-REV }} \geq 0.5$; for specific selectivity category percentages, see Table 1).

The order of a song stimulus can be altered in several ways. Reverse order song is a stimulus in which the temporal order within each syllable remains intact, but the sequence of syllables is reversed. For example, if each syllable is represented by a letter, then forward versus reverse order song is analogous to $\mathrm{ABC}$ versus CBA. In adult neurons, responses to reverse order stimuli are significantly less than those to forward stimuli (Doupe, 1997). In contrast, many $60 \mathrm{~d}$ LMAN neurons responded strongly to the "reverse order" manipulation of BOS and tutor song; in fact, some neurons did not discriminate between forward and reverse order stimuli. Figure $3 A$ shows such a neuron with strong responses to both reverse order BOS (BOS ro, third panel) and forward BOS. Of those LMAN neurons tested, 39\% were similar to the neuron in Figure $3 A$; these neurons were selective for forward compared with reversed stimuli but responded equivalently to forward and reverse order stimuli $\left(d_{\text {FOR-REV }}^{\prime} \geq 0.5\right.$ but $\left.-0.5<d_{\text {FOR-RO }}^{\prime}<0.5\right)$. Thus, this subset of $60 \mathrm{~d}$ neurons was sensitive to local order within a syllable but remained insensitive to the global order of syllables within a song. Other $60 \mathrm{~d}$ neurons were more adult-like; $66 \%$ were selective for forward relative to both reverse and reverse order song stimuli (see Table 1 for percentages of cells in the specific order selectivity categories). Overall, comparisons of mean RS from all LMAN neurons showed a small significant difference between forward BOS and reverse order BOS (paired $t$ test, $p<0.0021 ; n=41$ ) but not between forward tutor song and reverse order tutor song (paired $t$ test, $p<0.9728 ; n=29$ ).

\section{LMAN responses to BOS and tutor song}

The availability of both tutor song and the bird's own plastic song at this age allowed a comparison of neural responses to these two behaviorally important stimuli. LMAN neurons at $60 \mathrm{~d}$ had a variety of preferences for BOS versus tutor song. Some LMAN neurons preferred BOS to tutor song, others preferred tutor song to BOS, and many showed no preference, responding equally well to both stimuli (Fig. $4 A$ ). To describe the preference of a neuron,

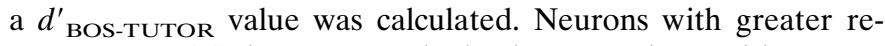
sponses to BOS than to tutor had values $>0$; those with greater responses to tutor song than to BOS had values $<0$; and those responding equally to both songs had values of $\sim 0$. A plot of 

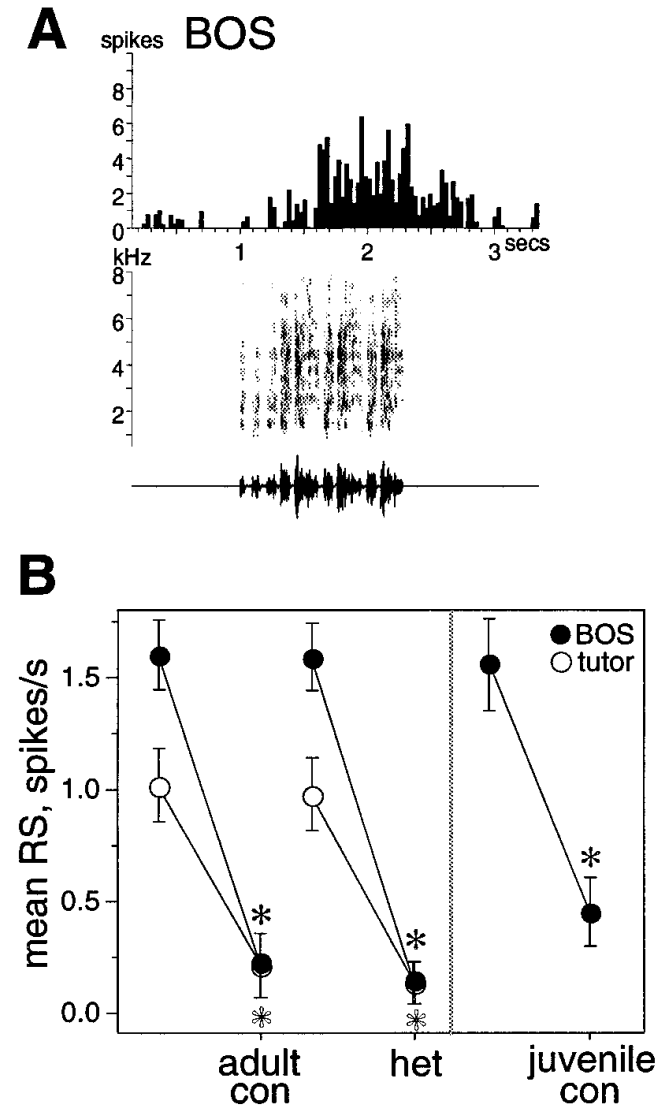
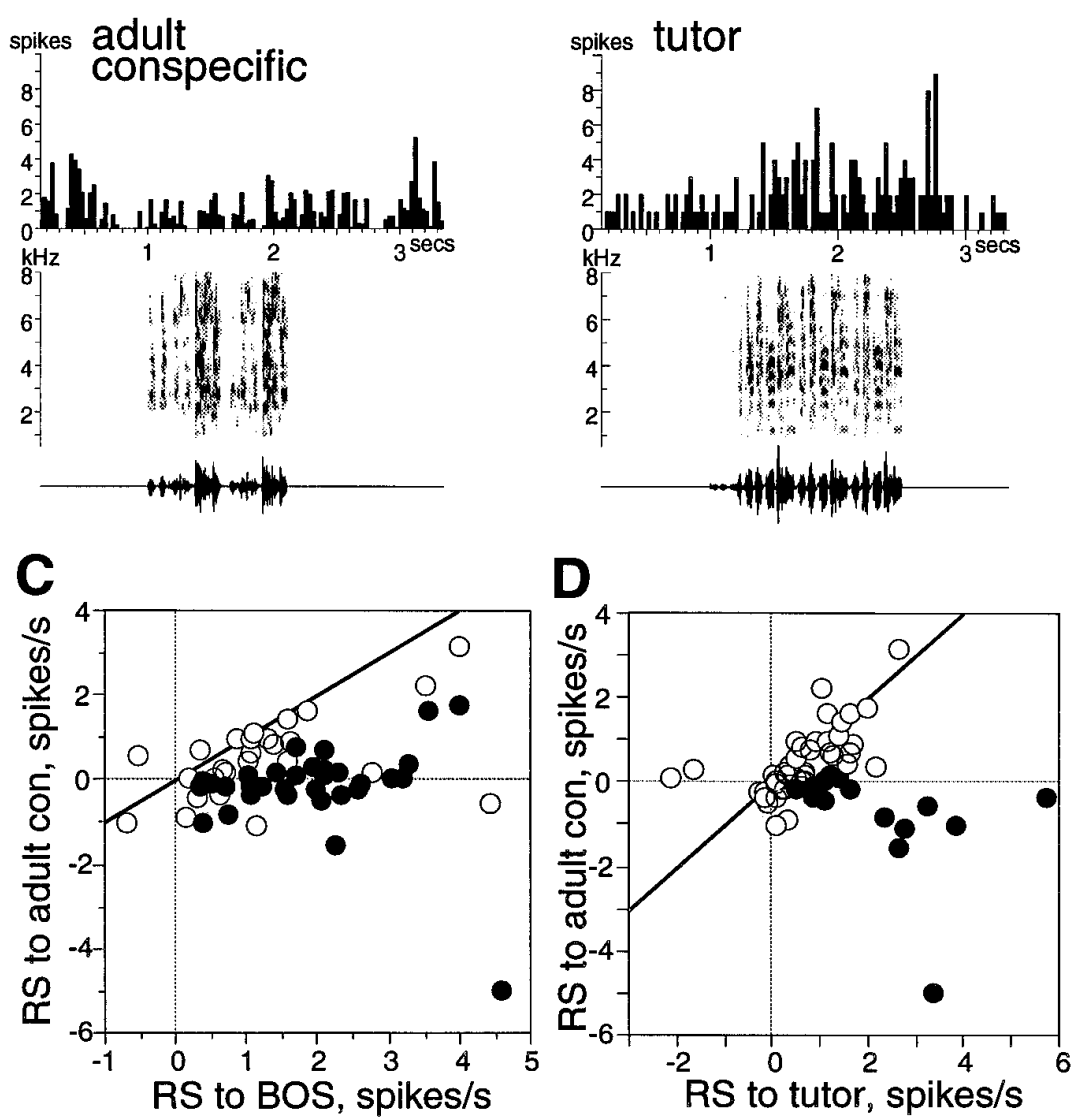

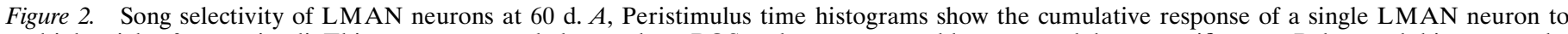

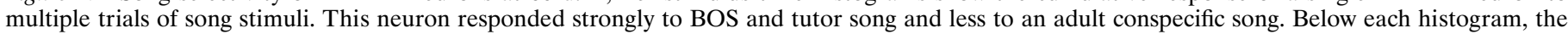

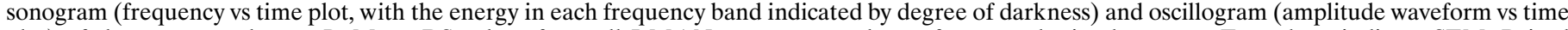

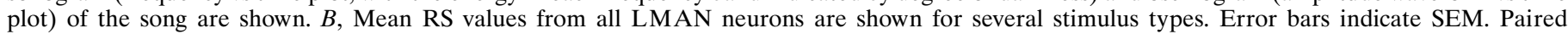

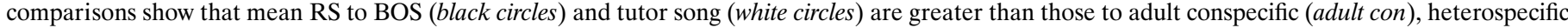

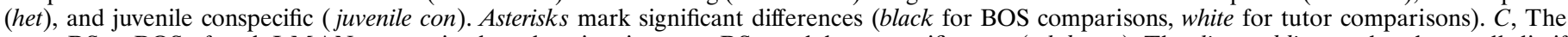

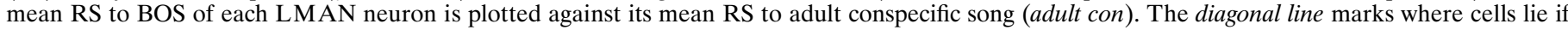

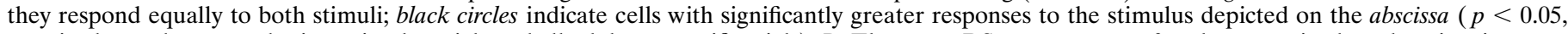

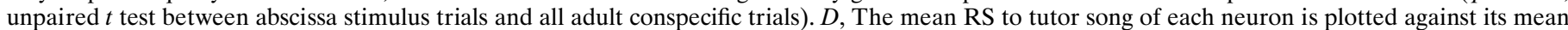
$\mathrm{RS}$ to adult conspecific song. Conventions are as in $C$.

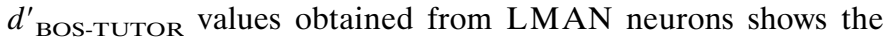
range and distribution of preferences (Fig. 4B). Although neurons were significantly responsive to BOS and/or tutor song, 34\% of them had no strong preference for either stimulus $(-0.5<$ $d^{\prime}{ }_{\text {BOS-TUTOR }}<0.5$; marked in gray in Fig. $4 B$ ). White circles in Figure $4 B$ signify neurons with an average response to the preferred stimulus that was at least twice as great as to the nonpreferred stimulus (i.e., $\mathrm{SI} \geq 0.67$ or $\leq 0.33$; for details, see Materials and Methods). In Figure $4 B$, most white circles lie outside of the gray unselective region, and most black circles lie within the gray region, indicating a good correspondence between these two measures of selectivity. Although individual neurons varied in their BOS versus tutor song preference, BOS elicited a greater average response than tutor song in LMAN (see Fig. 8E, black circles) (paired $t$ test, $p<0.0039 ; n=61$ ).

Because of the variable quality of plastic song, it was possible that neurons without a strong BOS preference were observed when the version of plastic song presented as BOS was one to which neurons were unresponsive. To test this, two or three different versions of BOS were presented in six experiments (19 neurons): neurons either responded equally well to all versions of plastic song or preferred the song that was most frequently pro-
Table 1. Comparisons of selectivity in LMAN and $X$

\begin{tabular}{lll} 
Selectivity category & LMAN & X \\
\hline BOS $>$ tutor & $31 / 56(55 \%)$ & $19 / 49(39 \%)$ \\
BOS $>$ adult conspecific* & $36 / 47(77 \%)$ & $24 / 47(51 \%)$ \\
BOS $>$ juvenile conspecific & $17 / 30(57 \%)$ & $17 / 34(50 \%)$ \\
BOS $>$ heterospecific* & $43 / 51(84 \%)$ & $31 / 47(66 \%)$ \\
BOS $>$ reverse BOS & $34 / 47(72 \%)$ & $30 / 41(73 \%)$ \\
BOS $>$ reverse order BOS & $15 / 37(41 \%)$ & $15 / 32(47 \%)$ \\
Tutor $>$ BOS* & $6 / 56(11 \%)$ & $14 / 49(29 \%)$ \\
Tutor $>$ adult conspecific & $20 / 41(49 \%)$ & $26 / 48(54 \%)$ \\
Tutor $>$ heterospecific & $24 / 42(57 \%)$ & $33 / 51(65 \%)$ \\
Tutor $>$ reverse tutor & $16 / 37(43 \%)$ & $25 / 45(56 \%)$ \\
Tutor $>$ reverse order tutor* & $5 / 21(24 \%)$ & $19 / 37(51 \%)$
\end{tabular}

The ratio of selective cells to the total tested in each category is shown for LMAN and $\mathrm{X}$, followed by the percentages. Cells were considered selective if the $d^{\prime}$ value for the two stimuli compared was $\geq 0.5$.

*Comparisons for which the frequency of occurrence of selective cells was significantly different between LMAN and X neurons ( $\chi^{2}$ tests; $\chi^{2}=6.64$ for BOS $>$ adult conspecific; $p<0.0101 ; \chi^{2}=4.457$ for BOS $>$ heterospecific; $p<0.0349 ; \chi^{2}=5.404$ for tutor $>$ BOS; $p<0.0202 ; \chi^{2}=4.189$ for tutor $>$ reverse order tutor; $p<0.0408$ ). 

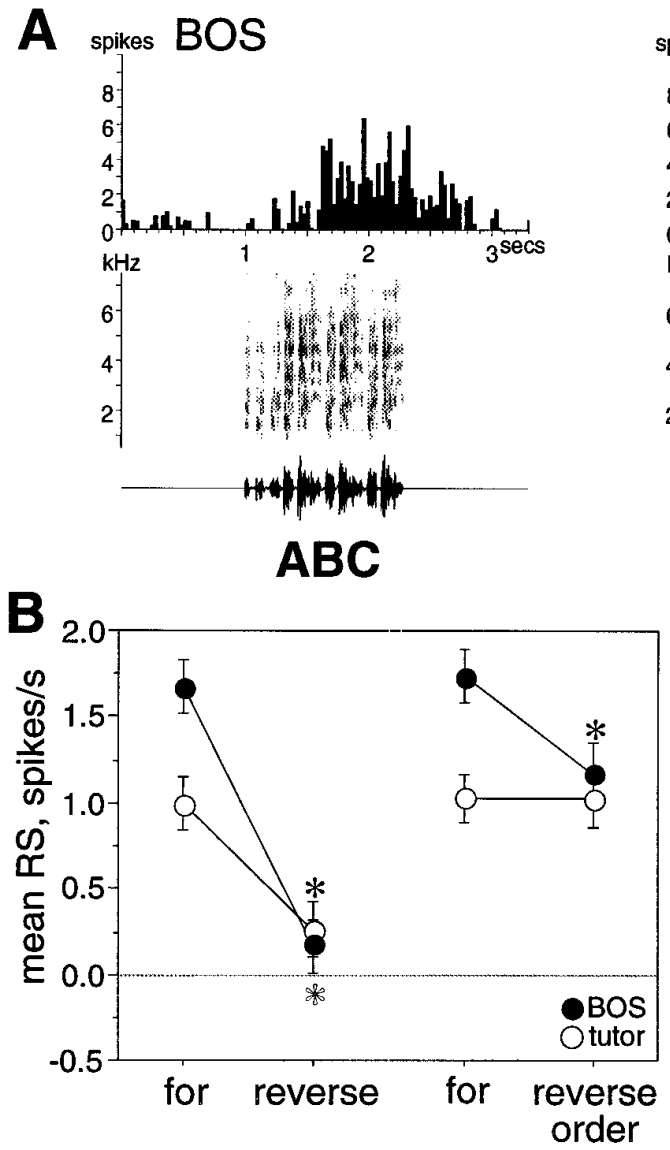
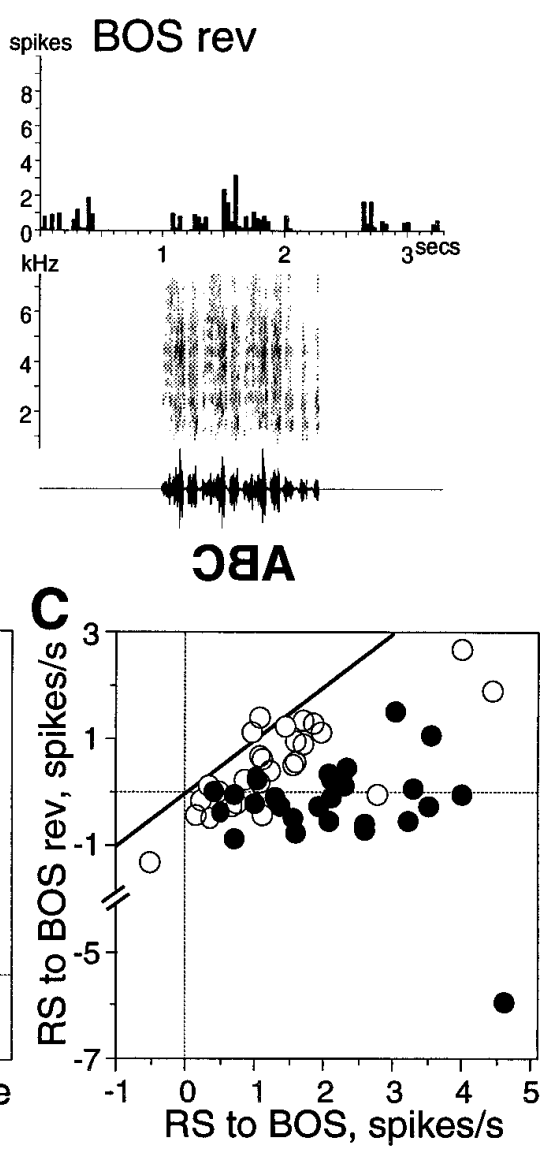
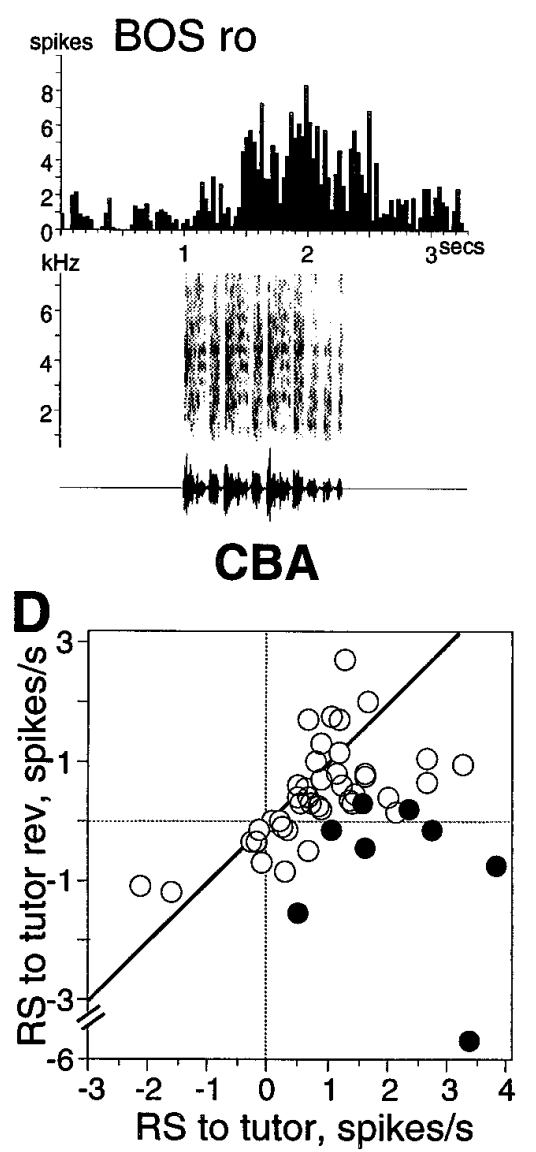

Figure 3. Order selectivity of LMAN neurons at $60 \mathrm{~d}$. $A$, Peristimulus time histograms show the strong response to BOS of a single LMAN neuron ( first panel) and decreased response to BOS when the stimulus was reversed (BOS rev, second panel). This cell responded well to the reverse order stimulus (BOS ro, third panel). B, Mean RS of all neurons to forward, reverse, and reverse order stimuli; paired comparisons show significantly greater responses to forward than to reverse song stimuli for both BOS (black circles) and tutor song (white circles) comparisons. Mean RS to reverse order BOS was slightly less than forward BOS in paired comparisons, whereas no significant difference existed between forward tutor song and reverse order tutor song. Asterisks indicate significant differences (black for BOS comparisons, white for tutor comparisons). Error bars represent SEM. $C$, The mean RS to BOS of each neuron is plotted against its mean RS to reverse BOS (BOS rev). The diagonal line indicates where cells lie if they respond equally to both stimuli. Cells with significantly greater responses to forward than to reverse stimuli are marked with black circles ( $p<0.05$, unpaired $t$ test between forward song trials and corresponding reverse song trials). $D$, The mean RS to tutor song of each neuron is plotted against its mean RS to reverse tutor song (tutor rev). Conventions are as in $C$.

duced, called "BOS 1" (Fig. 4C). This song was used as BOS in all comparisons with other song stimuli in all experiments. On average, BOS 1 elicited a slightly greater response than other plastic song renditions (ANOVA, $F_{(2,47)}=3.861 ; p<0.0281$ ). Thus, selectivity measurements were unlikely to be biased by inappropriate BOS choice.

LMAN cells responding equally well to BOS and tutor song were not simply unselective neurons, because they also showed song and/or order selectivity. Figure $5 A$ plots the BOS versus tutor song preference ( $\left.d^{\prime}{ }_{\text {BOS-TUTOR }}\right)$ of individual neurons against their degree of song selectivity $\left(d^{\prime}{ }_{\text {BOS-ADULT CON } \text { and }}\right.$ $d^{\prime}$ TUTOR-ADULT CON); even neurons without a strong BOS versus tutor song preference (Fig. $5 A$, gray region) exceeded $d^{\prime}$ values of 0.5 in these song selectivity measures. Figure $5 B$ shows the result of categorizing neurons based on their $d^{\prime}$ values for different measures of selectivity. If a neuron had a $d^{\prime}$ value $\geq 0.5$ for any one of four selectivity categories (BOS-adult conspecific, tutoradult conspecific, BOS-BOS reverse, and tutor-tutor reverse), it was considered selective. Classified in this way, $68 \%$ of neurons that responded equally well to BOS and tutor song were selective, and only five neurons in this class completely lacked such selec- tivity. This small fraction of cells recorded (9\%) resembled $30 \mathrm{~d}$ neurons, which respond equally well to all song types.

The graph in Figure $5 \mathrm{~A}$ also shows that neurons preferring BOS over tutor song are also strongly selective for BOS relative to adult conspecific song; likewise, neurons preferring tutor song relative to BOS also maintained this preference when comparing tutor responses with those of other adult conspecifics. Thus, the preference of a neuron for BOS or tutor song was consistent across comparisons with other song stimuli (e.g., conspecific, heterospecific, reverse, and reverse order song; all data not shown). This supports the idea that these neurons respond specifically to BOS or tutor song.

\section{Song and order selectivity of $X$ neurons at $60 \mathrm{~d}$}

To investigate circuitry that contributes to the selectivity of LMAN, neurons were recorded in $\mathrm{X}$, the first nucleus in the AF pathway (Fig. $1 C$ ). As in LMAN, these neurons $(n=56)$ also exhibited song and order selectivity at $60 \mathrm{~d}$. Figure $6 A$ illustrates the song selectivity of a single $\mathrm{X}$ neuron, which had robust responses to BOS and tutor song and weak responses to an adult conspecific song. The mean RS of all X neurons is shown for each 


$$
\text { A tutor }>\text { BOS }
$$
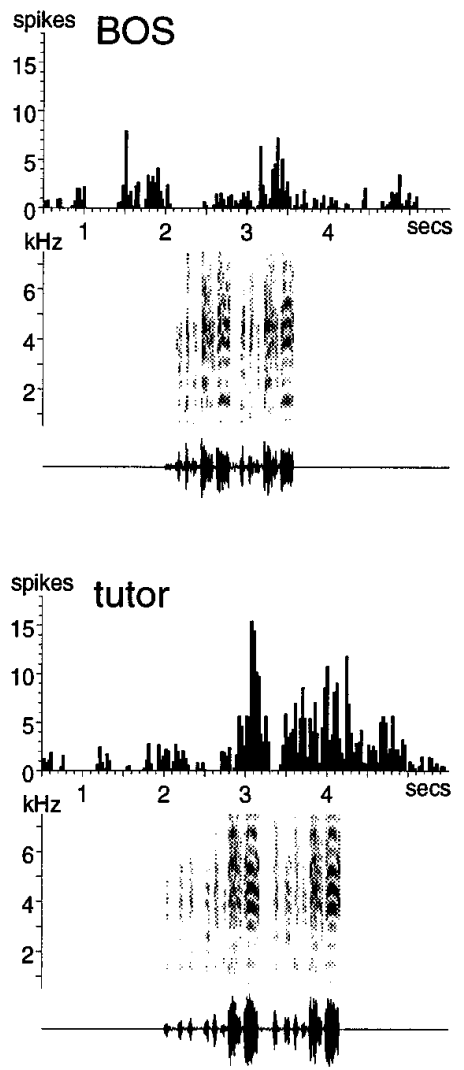

BOS=tutor

$\left(d^{\prime}=0.30\right)$
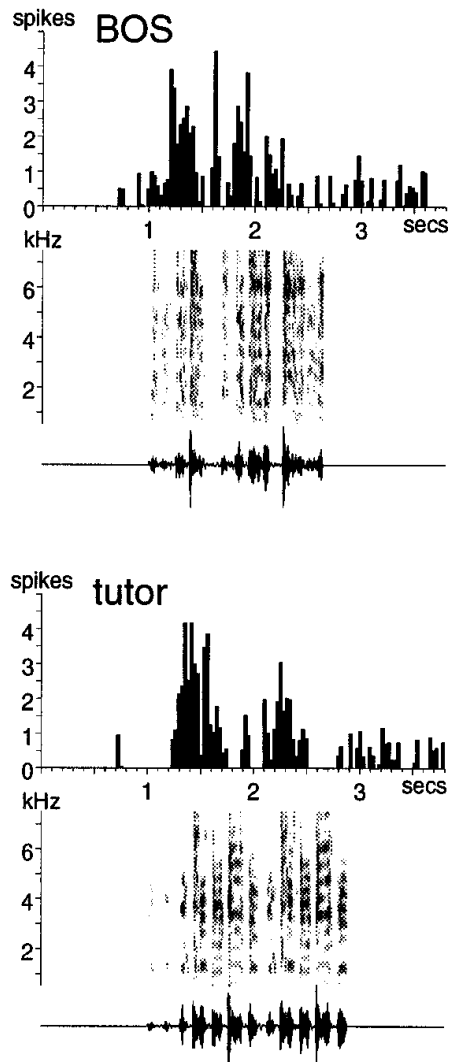

BOS > tutor

$\left(d^{\prime}=2.33\right)$
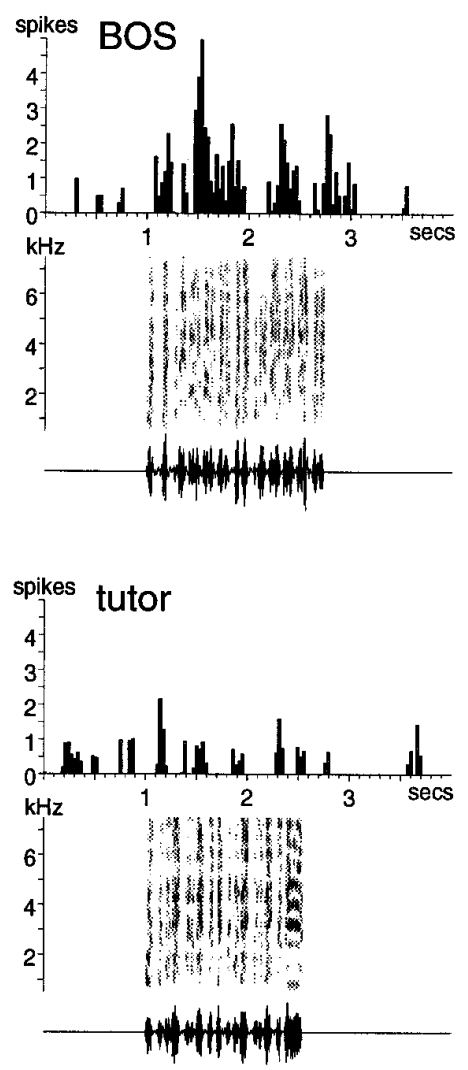
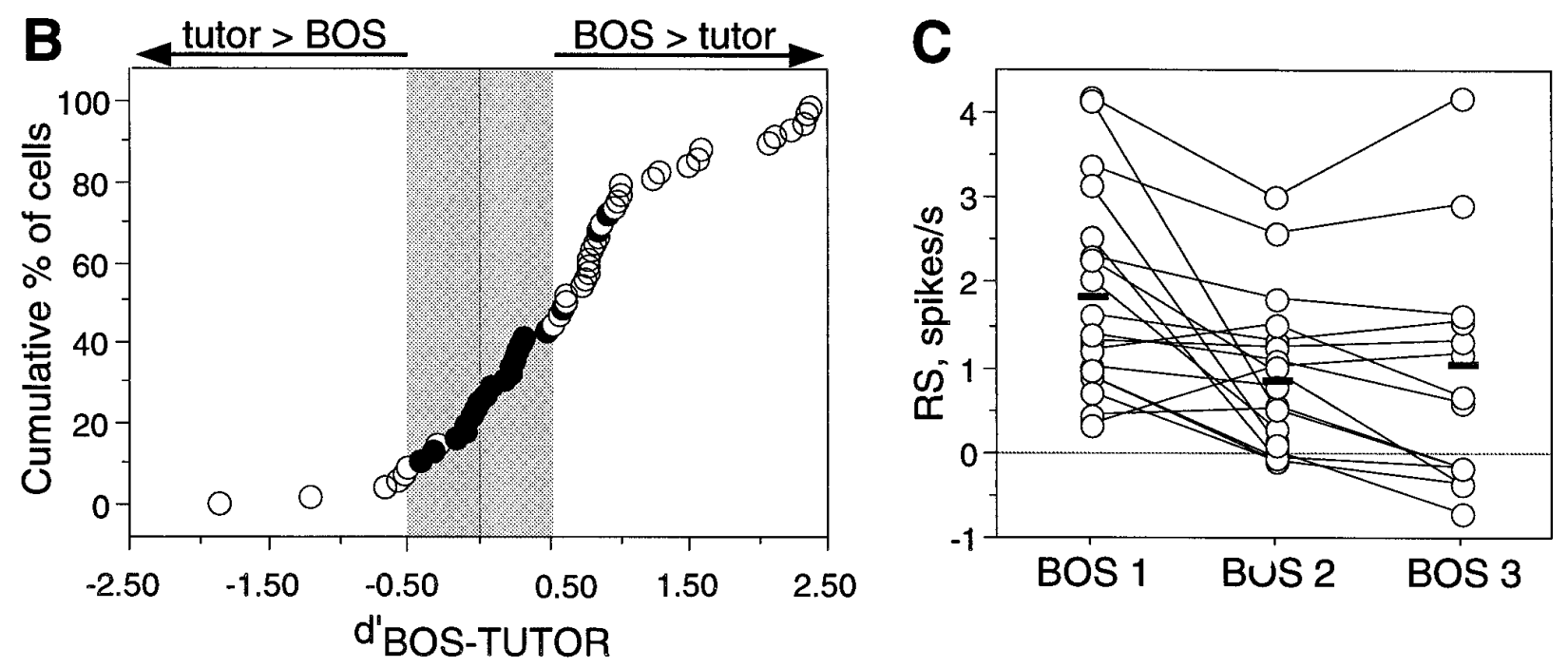

Figure 4. BOS versus tutor song preferences of LMAN neurons at $60 \mathrm{~d}$. $A$, Pairs of peristimulus time histograms for three different neurons show the range of preferences for BOS versus tutor song encountered in LMAN. The first pair shows a cell that responded more to the tutor song than to BOS; the second pair is from a neuron that responded equally well to both stimuli; and the third pair is from a cell that responded more to BOS than to its

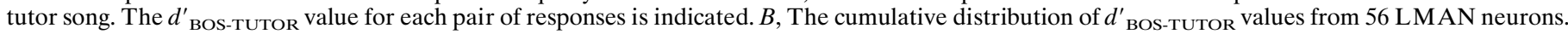
A white circle refers to a neuron with a response to the preferred stimulus that was at least twice as great as that to the nonpreferred stimulus, as determined from the SI. Gray shading indicates the region of $d^{\prime}$ values considered unselective $\left(-0.5<d^{\prime}<0.5\right)$. $C$, Responses of 19 cells to different versions of plastic song, named $B O S 1, B O S 2$, and $B O S 3$. BOS 1 is the song most frequently produced by the bird. The mean RS of all cells to each version is shown with thick black lines. 

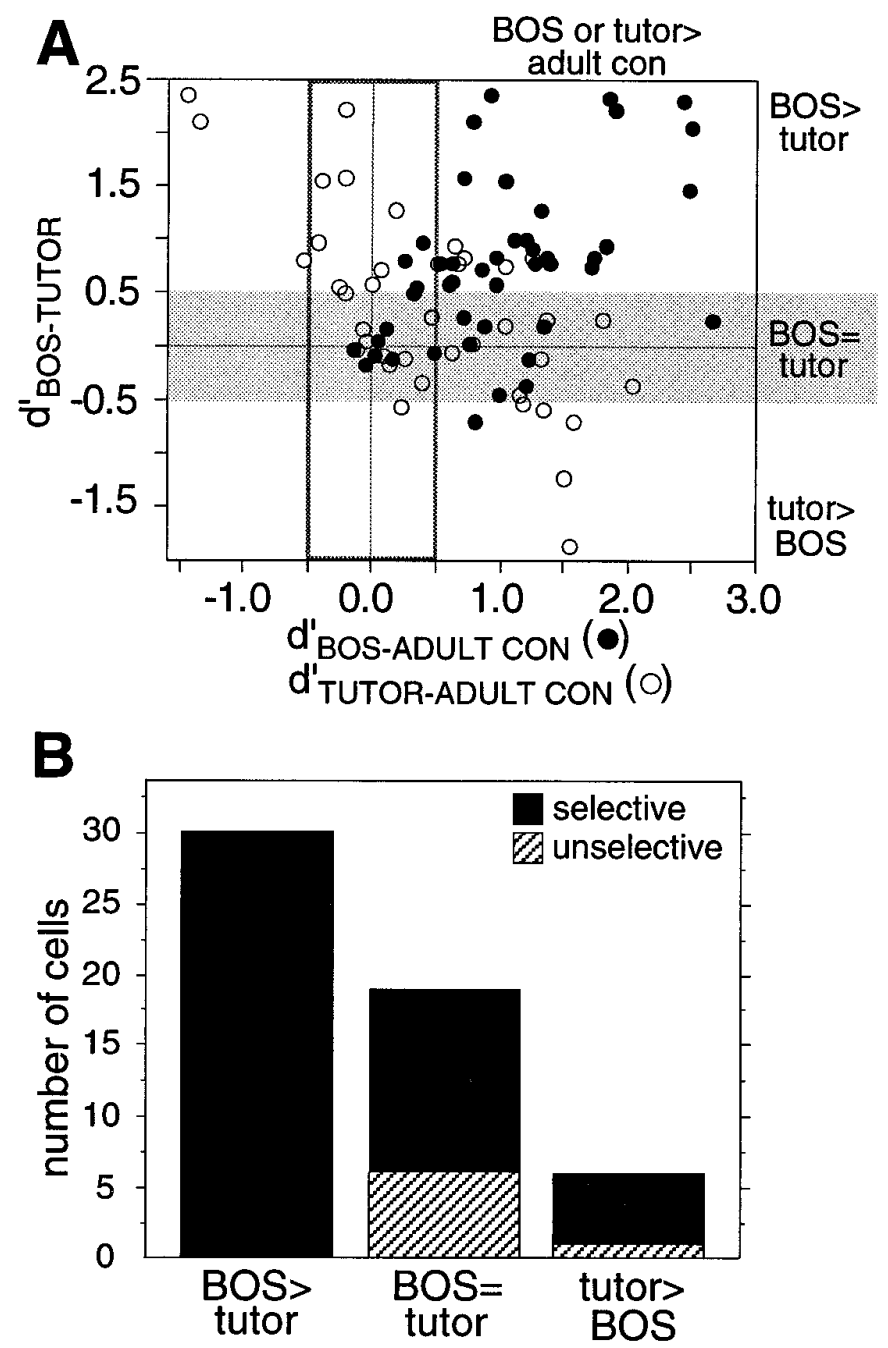

Figure 5. Selectivity of LMAN neurons with equal responses to BOS and tutor song. $A$, The BOS versus tutor song preference of each neuron $\left(d_{\text {BOS-TUTOR }}^{\prime}\right)$ is plotted against its degree of song selectivity, as measured by $d^{\prime}$ BOS-ADULT CON (black circles) and $d^{\prime}$ TUTOR-ADULT CON (white circles). The gray horizontal band highlights those cells with equal responses to BOS and tutor song. Note that many of these cells exceed 0.5 along the song selectivity axis, thus displaying significant song selectivity. $B$, Each LMAN neuron was classified according to its $d^{\prime}$ values for various comparisons of selectivity. BOS $>$ tutor neurons had $d^{\prime}{ }_{\text {BOS-TUTOR }} \geq 0.5$; $B O S=$ tutor neurons had $-0.5<d^{\prime}{ }_{\text {BOS-TUTOR }}<0.5$, and tutor $>B O S$ song neurons had $d^{\prime}$ BOS-TUTOR $\leq-0.5$. To be counted as selective, a neuron had to have $d^{\prime} \geq 0.5$ in at least one of the following four selectivity categories: BOS-adult conspecific, tutor-adult conspecific, BOS-BOS reverse, or tutor-tutor reverse.

stimulus type in Figure $6 B$; BOS and tutor songs evoked significantly greater responses than adult and juvenile conspecific songs and heterospecific songs (paired $t$ tests, $p<0.0001$ for BOS-adult conspecific, $n=49$; for BOS-heterospecific, $n=53$; and for tutor-heterospecific, $n=53$; $p<0.0026$ for BOS-juvenile conspecific, $n=35 ; p<0.0005$ for tutor-adult conspecific, $n=49$ ). On average, there was no significant difference between BOS and tutor song responses (see Fig. $8 E$, white circles) (paired $t$ test, $p<$ $0.2950 ; n=52$ ). The song selectivity of individual X neurons is illustrated with scatter plots that compare the mean RS to BOS (Fig. 6C) and tutor song (Fig. 6D) of each neuron with its mean $\mathrm{RS}$ to adult conspecific song. All points below the diagonal lines represent $\mathrm{X}$ neurons that responded more to BOS or tutor song than to adult conspecific songs. The percentages of selective $\mathrm{X}$ cells in each song selectivity category are listed in Table 1.

$\mathrm{X}$ neurons were also order selective, responding more to BOS or tutor song than to completely reversed stimuli. An example of an order selective $\mathrm{X}$ neuron is shown in Figure $7 A$ (first two panels). Comparisons of mean RS of all $\mathrm{X}$ neurons showed that forward BOS and tutor song elicited significantly stronger responses than the corresponding reverse stimuli (Fig. 7B) (paired $t$ tests, $p<0.0001$ for BOS-reverse BOS, $n=45$; and for tutorreverse tutor, $n=46$ ). Most $\mathrm{X}$ cells responded more to forward than to reverse stimuli; when the mean RS to BOS (Fig. $7 C$ ) or tutor song (Fig. $7 D$ ) of each neuron is compared with the corresponding reverse stimulus, most cells lie below the diagonal line. Eight-two percent of $\mathrm{X}$ neurons tested were selective for forward relative to reverse stimuli (see Table 1 for specific selectivity category percentages).

As in LMAN, some $\mathrm{X}$ neurons had strong responses to reverse order stimuli (Fig. 7A, BOS ro, third panel). Of those $\mathrm{X}$ neurons tested, $30 \%$ were selective for forward stimuli relative to reverse but responded equally well to forward and reverse order stimuli $\left(d_{\text {FOR-REV }}^{\prime} \geq 0.5\right.$ but $-0.5<d^{\prime}{ }_{\text {FOR-RO }}<0.5$ ). In contrast, $63 \%$ resembled adult neurons, being selective for forward stimuli over both reverse and reverse order song stimuli ( $d_{\text {FOR-REV }}^{\prime} \geq 0.5$ and $d_{\text {FOR-RO }}^{\prime} \geq 0.5$; see Table 1 for percentages of cells in specific selectivity categories). On average, $\mathrm{X}$ neurons responded significantly less to reverse order stimuli when compared with forward responses (Fig. 7B) (paired $t$ test, $p<0.0003$ for BOS-reverse order BOS, $n=35 ; p<0.0264$ for tutor-reverse order tutor, $n=$ 38). Thus, sensitivity to the global order of song is in the process of developing at $60 \mathrm{~d}$.

Of those $\mathrm{X}$ neurons with equal responses to BOS and tutor song $\left(-0.5<d^{\prime}{ }_{\text {воs-тuтor }}<0.5\right), 63 \%$ exhibited at least one aspect of song or order selectivity (specifically, $d^{\prime}{ }_{\text {BOS-ADULT CON }}$ $\geq 0.5, d^{\prime}{ }_{\text {TUTOR-ADULT CON }} \geq 0.5, d^{\prime}{ }_{\text {BOS-REV }} \geq 0.5$, or $d^{\prime}$ TUT-REV $\geq 0.5$ ). Only $10 \%$ of $X$ cells recorded responded equally well to all of these song stimuli. As in LMAN, the BOS or tutor song preference of an $\mathrm{X}$ neuron was consistent across different song comparisons (data not shown).

\section{A comparison of LMAN and $X$ responses}

Although they shared song and order selectivity, LMAN and X differed from each other in some respects. LMAN neurons had a significantly lower mean spontaneous rate than $\mathrm{X}$ neurons did (Fig. 8A) (mean and SEM, $1.60 \pm 0.25$ spikes/sec for LMAN, $40.04 \pm 3.84$ spikes/sec for X; unpaired $t$ test, $p<0.0001)$. Also, broad band noise bursts often inhibited LMAN neurons, whereas they elicited robust firing from $\mathrm{X}$ neurons. The mean RS to a broad band noise burst (300 msec) of LMAN neurons was significantly less than that of $\mathrm{X}$ neurons (Fig. $8 B$ ) (unpaired $t$ test, $p<0.0001)$.

LMAN and $\mathrm{X}$ did not differ significantly in their degree of selectivity, whether measured with $d^{\prime}$ or SI values (Fig. 8C). Although LMAN tended to have higher mean SI values than $\mathrm{X}$ did, paired comparisons between nuclei found no significant differences in selectivity when measured with either SI or $d^{\prime}$. In general, LMAN and $\mathrm{X}$ shared the same range of BOS versus tutor song preferences (Fig. 8D). As did LMAN, many $\mathrm{X}$ neurons responded equally well to both stimuli (compare $33 \%$ in $\mathrm{X}$ to $34 \%$ in LMAN with $-0.5<d^{\prime}{ }_{\text {BOS-TUTOR }}<0.5$ ). On average, LMAN responded more to BOS than to tutor song, whereas in X, the mean RS values to these two stimuli were equivalent (Fig. $8 E$ ). This difference is likely attributable to the greater number of 

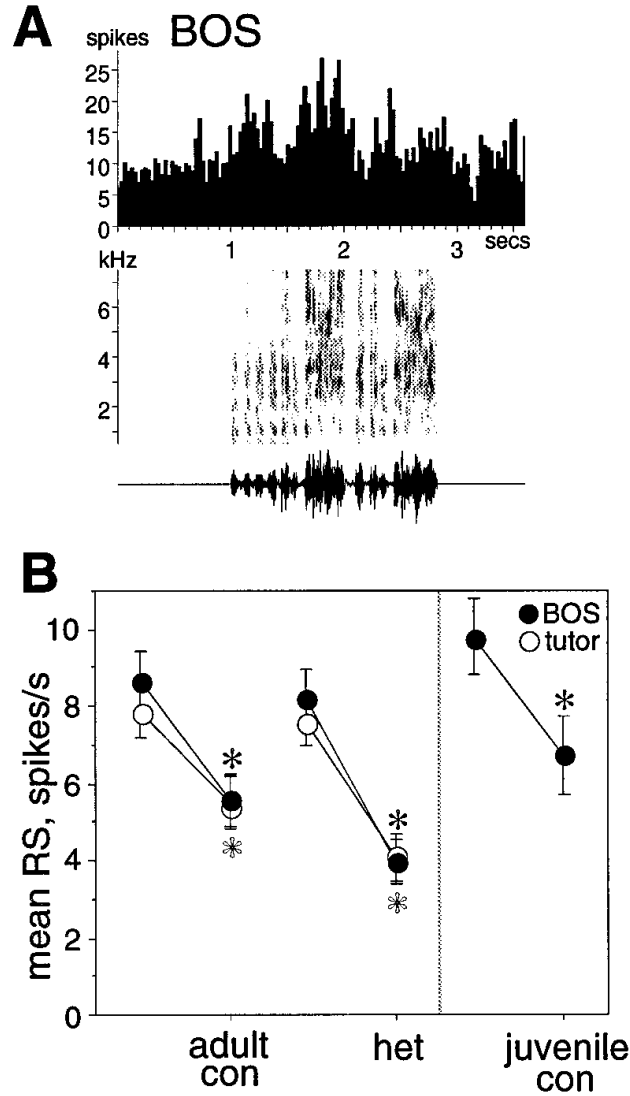
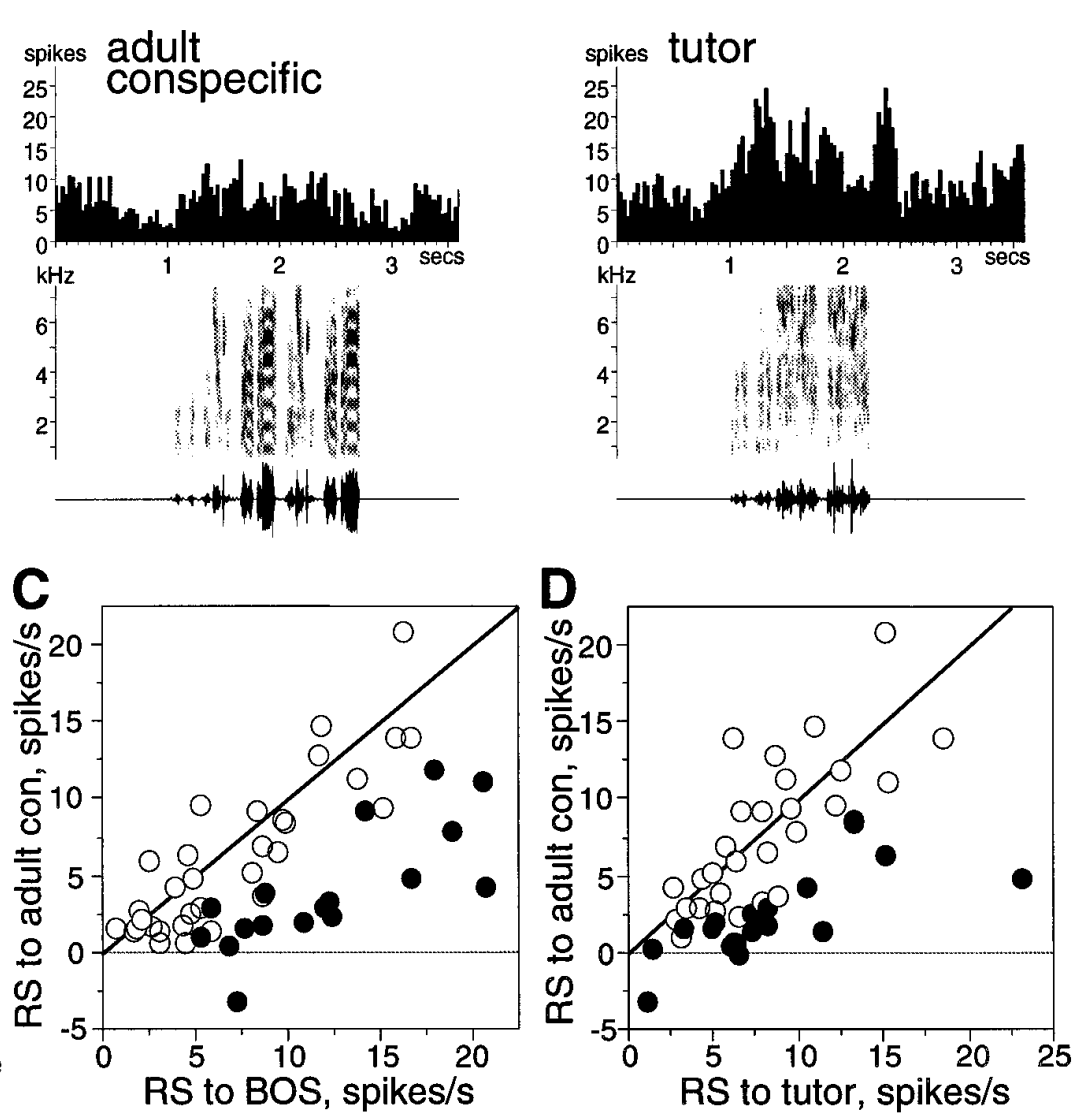

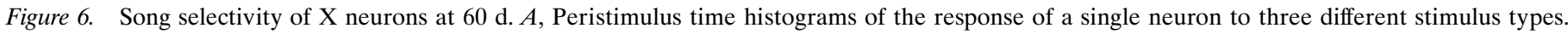

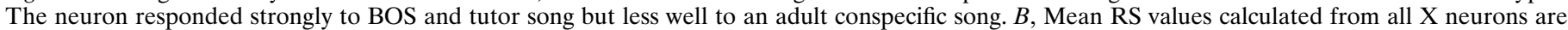

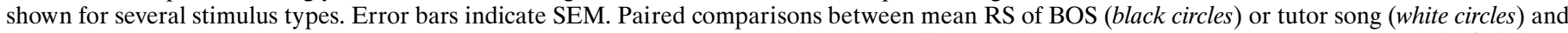

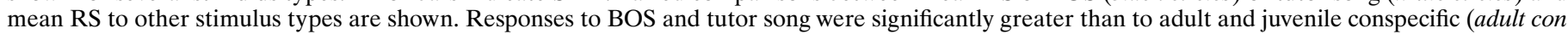

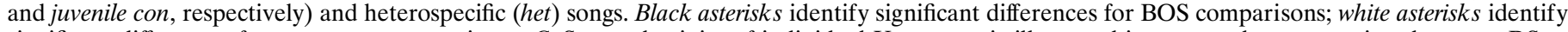

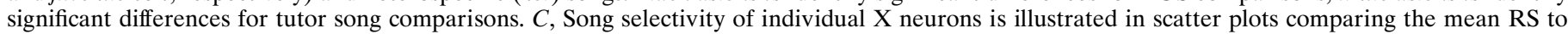

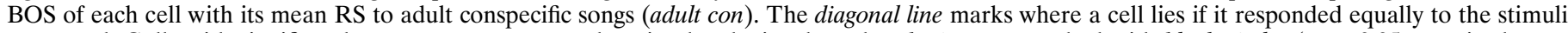

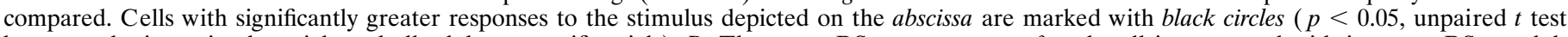

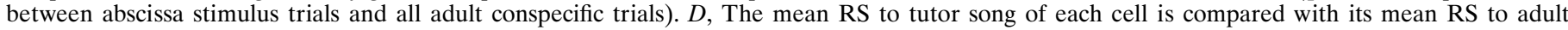
conspecific song. Conventions are as in $C$.

tutor-preferring neurons in $\mathrm{X}$ than in LMAN (i.e., neurons with $d_{\text {BOS-TUTOR }}^{\prime} \leq-0.5$ ).

The number of selective neurons in LMAN was significantly different from $\mathrm{X}$ for four selectivity categories (Table 1); LMAN had significantly more BOS $>$ adult conspecific and BOS > heterospecific neurons than $\mathrm{X}$ did, whereas $\mathrm{X}$ had more tutor $>$ BOS and tutor $>$ reverse order tutor neurons than LMAN. These two nuclei also differed in the frequency of inhibitory responses; of all selective responses found in each nucleus (i.e., all $d^{\prime} \geq 0.5$ ), significant inhibition to nonpreferred stimuli $(p<0.05$, paired $t$ test between the firing rate during a stimulus and spontaneous rate) occurred in $41 \%$ of LMAN cases and in only $6 \%$ of X cases. Thus, inhibition was a component of the selective responses of LMAN more frequently than those of $\mathrm{X}\left(\chi^{2}\right.$ test, $\left.p<0.0001\right)$.

\section{Comparisons between individual birds}

The $d^{\prime}$ BOs-TUTOR values of LMAN neurons from individual birds clustered in certain regions of the preference range, rather than spanning the full range (Fig. $9 A$, ordinate; mean and SEM of $d^{\prime}$ BOs-Tutor values for each bird are also shown in Fig. 9B,C).

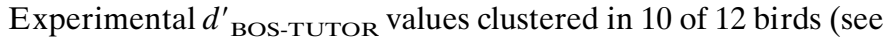
Materials and Methods), and this frequency of clustering was greater than expected by chance (sign test, $p<0.0161$ ). Such clustering was also apparent for $\mathrm{X}$ neurons and for LMAN and $\mathrm{X}$ neurons considered together (for X, 10 of 13 birds were clustered; $p<0.036$; for $\mathrm{X}$ and LMAN together, 14 of 16 birds were clustered; $p<0.0019)$. Thus, something specific to each bird could explain the BOS versus tutor song preference of its neurons.

These differences between the mean $d^{\prime}$ Bоs-TUTOR of each bird could not be accounted for by conditions that varied between experiments. Slight intensity differences between BOS and tutor song stimuli did not affect the BOS versus tutor song preference of neurons from an individual bird (see Materials and Methods; for peak intensity, $r^{2}=0.033$ for LMAN; $r^{2}=0.041$ for $\mathrm{X}$; for relative values of mean intensity, correlations were also insignificant). Similarly, stimulus duration did not strongly correlate with a bird's BOS versus tutor song preference $\left(r^{2}=0.001\right.$ for LMAN; $r^{2}=0.055$ for $\left.\mathrm{X}\right)$. The duration of the experiment at the time when individual neurons were recorded also did not affect their $d^{\prime}{ }_{\text {BOS-Tutor values }}\left(r^{2}=0.143\right.$ for LMAN; $r^{2}=0.053$ for $\left.\mathrm{X}\right)$. Because differences in anesthesia depth between experiments could cause clustering of $d^{\prime}$ BOS-TUTOR values from each bird, the

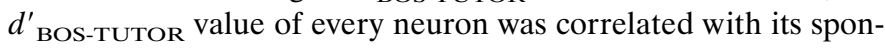
taneous rate and maximum RS to a song stimulus, both potential 
A
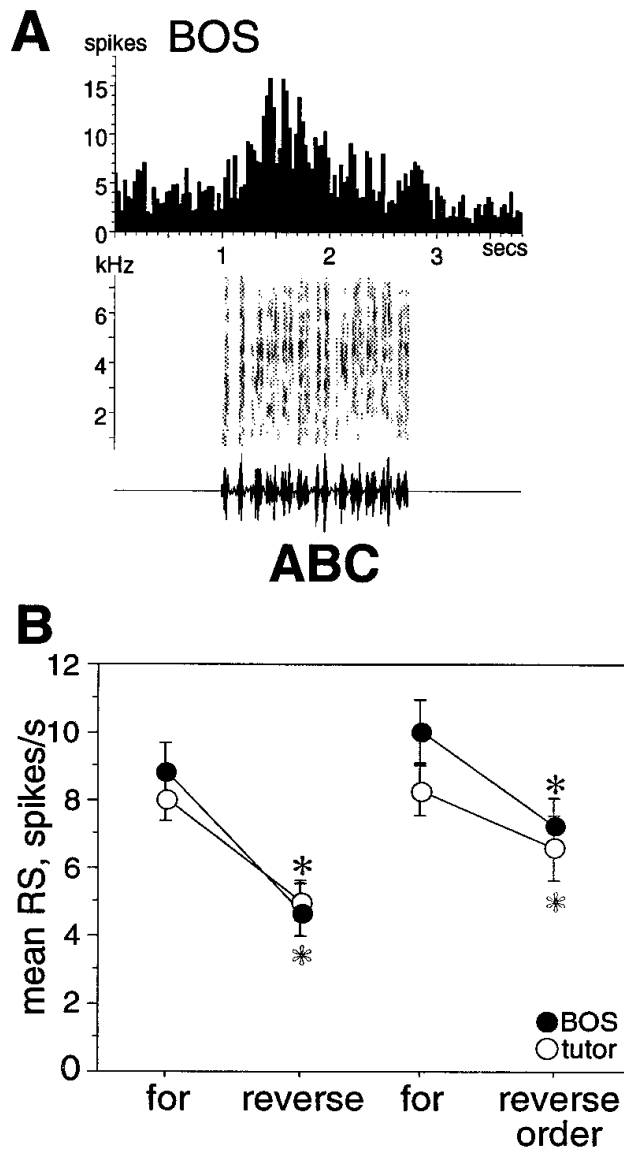

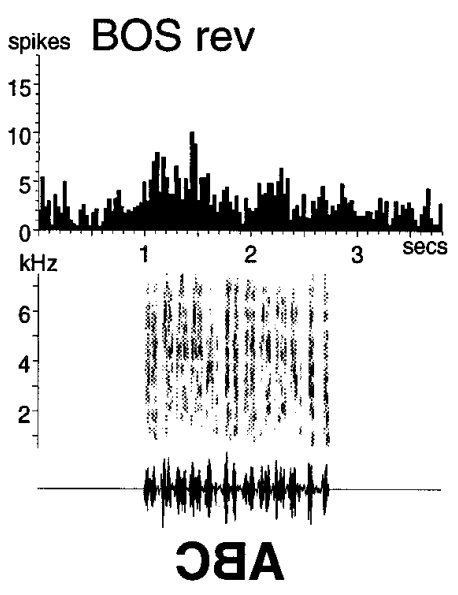

C

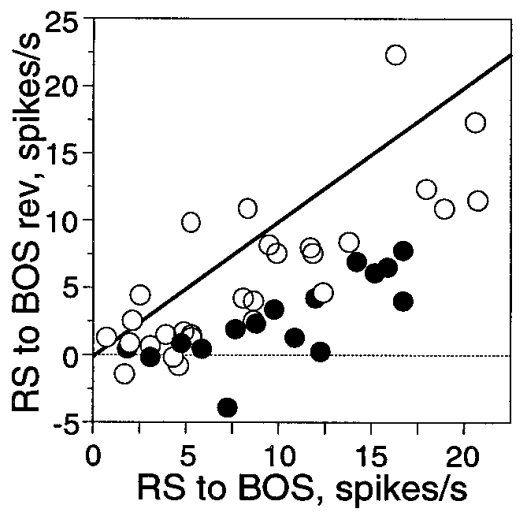

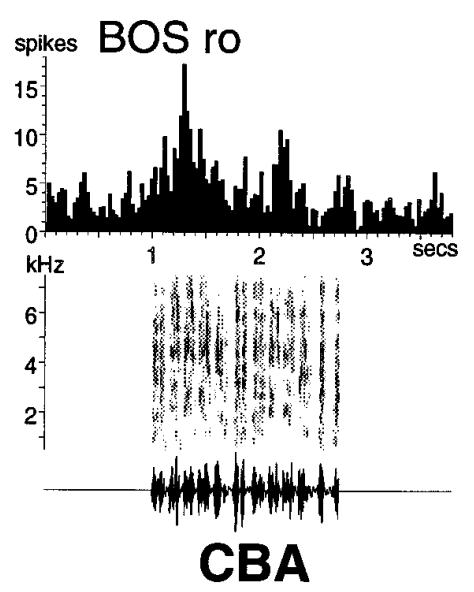

D

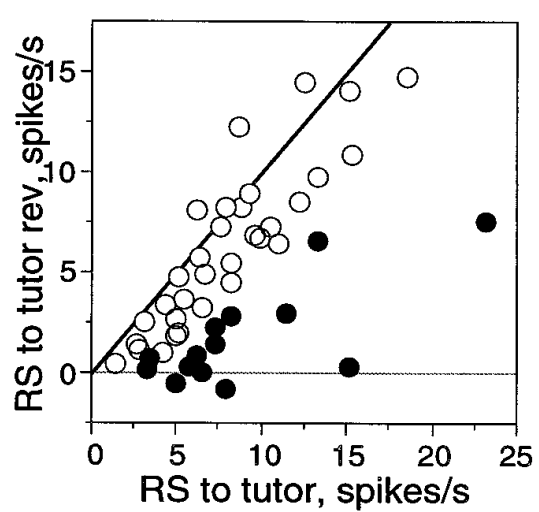

Figure 7. Order selectivity of $\mathrm{X}$ at $60 \mathrm{~d}$. A, Peristimulus time histograms of the responses of a single $\mathrm{X}$ neuron to three different stimuli. The BOS response was greatly reduced by completely reversing the song stimulus $(B O S \mathrm{rev})$. However, its response was not reduced by the reverse order stimulus (BOS ro). B, Mean RS values of all X neurons to forward, reverse, and reverse order stimuli. Paired comparisons show significantly greater responses to forward than to reverse and reverse order stimuli for both BOS (black circles) and tutor song (white circles) comparisons. Error bars indicate SEM. Asterisks mark significant differences (black for BOS comparisons, white for tutor comparisons). C, Order selectivity of individual X units is displayed in scatter plots comparing the RS to BOS of each neuron with its RS to reverse BOS (BOS rev). The diagonal line marks where cells lie if they responded equally to both stimuli; cells with significantly greater responses to forward than to reverse are marked with black circles $(p<0.05$, unpaired $t$ test between forward stimulus trials and corresponding reverse stimulus trials). $D$, The RS to tutor song of each neuron is compared with its RS to reverse tutor song (tutor rev). Conventions are as in $C$.

indicators of anesthesia depth. No association between the spontaneous rate of a neuron and its $d^{\prime}$ BOS-TUTOR value existed in LMAN or in $\mathrm{X}\left(r^{2}=0.049\right.$ for LMAN; $r^{2}=0.005$ for $\left.\mathrm{X}\right)$. Similarly, the maximum RS to a song stimulus of a neuron was

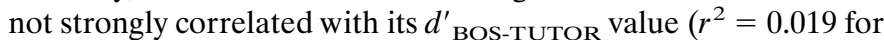
LMAN; $r^{2}=0.044$ for $\mathrm{X}$ ). Recording from different locations within LMAN could have biased the $d^{\prime}{ }_{\text {BOS-TUTOR values ob- }}$ tained if a topography of selectivity existed. Yet, comparisons of the location of each neuron along the dorsoventral, mediolateral, and anteroposterior axes of LMAN to its $d^{\prime}{ }_{\text {BOS-TUTOR value }}$ yielded no strong correlations $\left(r^{2}=0.085\right.$ for dorsoventral; $r^{2}=$ 0.033 for mediolateral; and $r^{2}=0.045$ for anteroposterior). Thus, no evidence for a topography of selectivity was found in LMAN. Together, these results indicate that clustering of $d^{\prime}$ BOS-TUTOR values in individual birds could not be explained by these particular differences between experiments.

To test whether the BOS versus tutor song preference of a bird depended on some aspect of its experience, the mean $d^{\prime}{ }_{\text {BOS- }}$ TUTOR value of each bird was compared with different measures of the bird's maturity. A comparison between a bird's mean

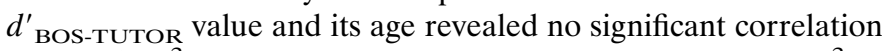
(Fig. $9 A)\left(r^{2}=0.055\right.$ for LMAN; data not shown for $\mathrm{X} ; r^{2}=$
0.018). A bird's maturity can also be measured in terms of its song development. The song maturity of each experimental bird was estimated using a similarity test and a stereotypy test (see Materials and Methods). The similarity test rated the similarity between BOS and tutor song. Comparing the final similarity score

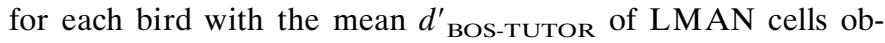
tained from each bird produced a moderate, significant correlation (Fig. 9B) $\left(r^{2}=0.453 ; p<0.0060\right)$. When BOS differed from tutor song, neurons preferred BOS; when BOS resembled tutor song, neurons responded equally to BOS and tutor song or more to tutor song. Because birds do not always produce perfect copies of tutor songs in adulthood, song similarity between the BOS and tutor song is an incomplete description of song maturity. Thus, another measure of maturity was used, which judged each bird's song stereotypy based on several renditions of its plastic song. Comparing the final stereotypy score for each bird with its mean $d^{\prime}$ BOS-TUTOR value of LMAN neurons resulted in a small but nearly significant correlation (Fig. $9 C)\left(r^{2}=0.273 ; p<0.0554\right)$. The similarity scores and stereotypy scores for each bird covaried, indicating that these two features of maturity develop together (Fig. 9D) $\left(r^{2}=0.668 ; p<0.0002\right)$. The $d^{\prime}{ }_{\text {Bos-TutoR }}$ values of individual cells were also compared with song test scores 


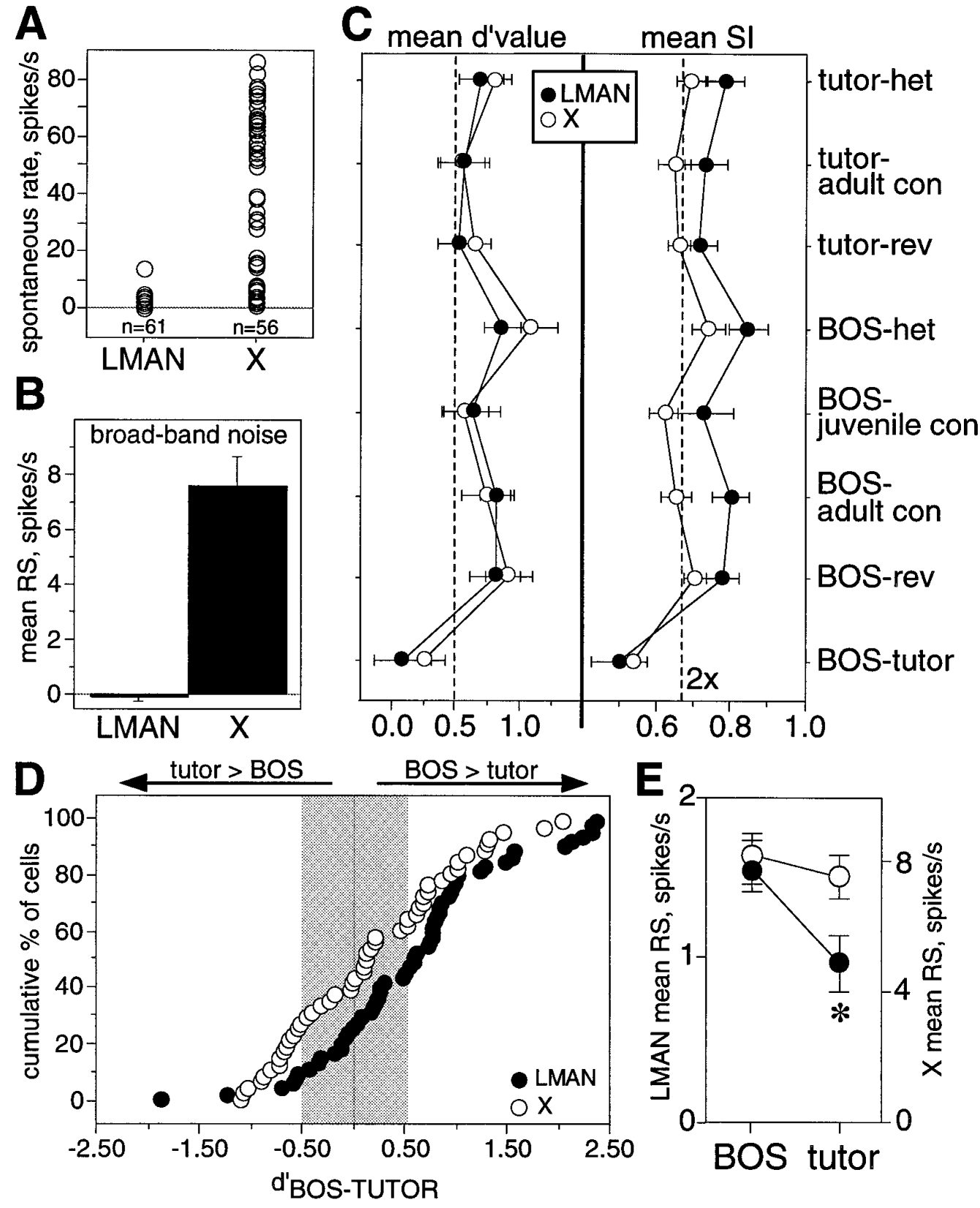

Figure 8. Comparisons of LMAN and $\mathrm{X}$ properties. $A$, Mean spontaneous firing rates for each LMAN and $\mathrm{X}$ neuron recorded. $B$, A histogram compares the mean RS of all LMAN neurons to a $300 \mathrm{msec}$ broad band noise burst with that of all $\mathrm{X}$ neurons. $C$, Mean $d^{\prime}$ value (left graph) and mean SI (right graph) for each selectivity category are shown for LMAN (black circles) and $\mathrm{X}$ (white circles). Error bars indicate SEM. Means were calculated from the average SI or $d^{\prime}$ value of each nucleus from each bird. The dotted line at 0.5 in the left graph marks the criterion value for a selective response. In the right graph, means plotted to the right of the dotted line $(2 \times)$ denote average responses to the preferred stimulus that were at least two times greater than average responses to the nonpreferred stimulus. Abbreviations are defined in legends to Figures 6 and 7. $D$, The cumulative distribution of $d^{\prime}$ BOS-TUTOR values is shown for neurons in LMAN (black circles) and X (white circles). E, The mean RS of each nucleus to BOS and tutor song is shown; the left axis corresponds to LMAN values (black circles), and the right axis corresponds to $\mathrm{X}$ values (white circles). Error bars indicate SEM. The difference in RS between BOS and tutor song was significant for LMAN only (black asterisk). to weigh each bird's contribution to the correlation by the number of cells recorded from that bird. These comparisons yielded similar results (Fig. 9A-C, dotted lines) (for age, $r^{2}=0.075 ; p<$ 0.0411 ; for similarity test, $r^{2}=0.257$; $p<0.0001$; and for stereotypy test, $\left.r^{2}=0.150 ; p<0.0036\right)$. These correlations with song maturity indicate that a bird's stage of song learning could be related to the selectivity of its neurons.

The same analyses were completed for X neurons; weaker correlations in the same direction as those for LMAN resulted. A comparison between a bird's song similarity score and the BOS versus tutor song preference of its $\mathrm{X}$ neurons produced a small, insignificant correlation (data not shown; mean $d_{\text {BOS-TUTOR }}^{\prime}$ values vs similarity scores, $r^{2}=0.173 ; p<0.1091$; individual

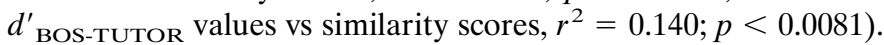
Comparing a bird's song stereotypy to the BOS versus tutor song preference of its $\mathrm{X}$ neurons also yielded small and insignificant correlations (data not shown; mean $d^{\prime}$ BOS-TUTOR values vs ste- reotypy scores, $r^{2}=0.107 ; p<0.2337$; individual $d^{\prime}$ BOS-TUTOR values vs stereotypy scores, $\left.r^{2}=0.049 ; p<0.1305\right)$.

\section{DISCUSSION}

This study demonstrates that in 1 month, AF neurons have changed considerably from the unselective neurons found in 30 -d-old birds. By $60 \mathrm{~d}$, these neurons showed significant song and order selectivity for BOS and tutor song. On average, neurons responded more to BOS or tutor song than to conspecific and heterospecific songs. AF neurons also decreased their responses to BOS and tutor song when these songs were reversed, demonstrating an ability to discern fine temporal properties of song. Comparisons of responses to BOS and tutor song revealed a range of preferences in LMAN and $\mathrm{X}$; most neurons preferred BOS, some preferred tutor song, and others responded equally to both. Many neurons with equal responses to BOS and tutor song 

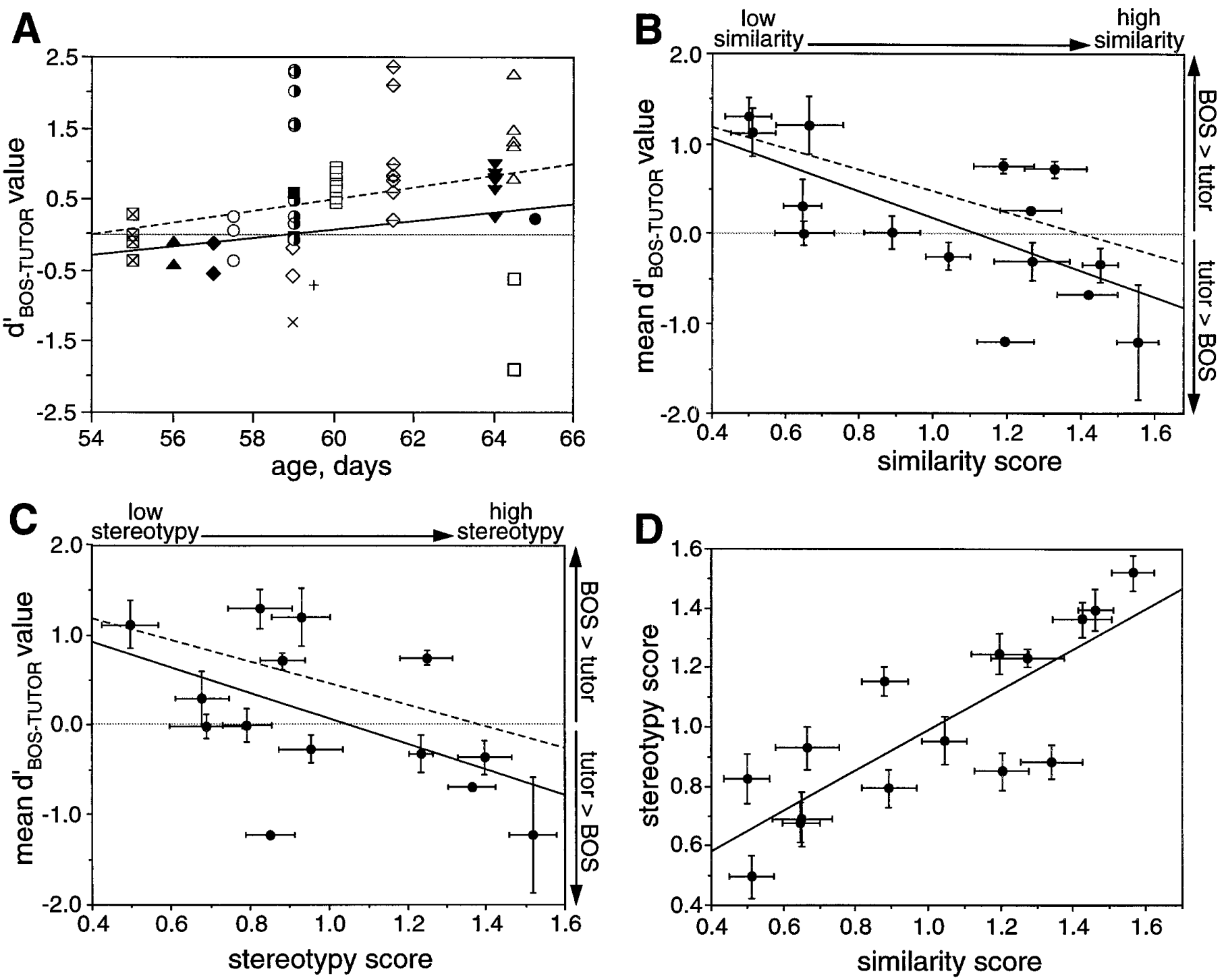

Figure 9. Clustering of BOS versus tutor song preferences of LMAN neurons from individual birds and their correlations with measures of maturity. In each graph, the solid line marks the linear least squares fit of the mean data, and the dotted line marks the linear least squares fit of individual cell

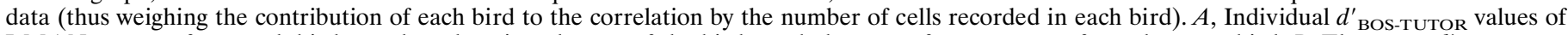
LMAN neurons from each bird are plotted against the age of the bird; symbol types refer to neurons from the same bird. $B$, The mean $d^{\prime}$ вов-тUтов value from LMAN neurons of each bird is plotted against the bird's final similarity score. Error bars indicate SEM. Because individual scores were normalized by each observer's mean score, a value of 0.4 refers to a song with no similarity to the tutor song, and 1.6 refers to a song with high similarity to the tutor song (see Materials and Methods). $C$, The mean $d^{\prime}$ воs-тUтов value from LMAN neurons of each bird is plotted against the bird's final stereotypy score. Error bars indicate SEM. For the same reason as in $B$, a score of 0.4 represents low stereotypy, and a score of 1.6 corresponds to high stereotypy. $D$, The similarity score of each bird is plotted against its stereotypy score. Error bars indicate SEM.

were not simply immature, because they exhibited song or order selectivity.

\section{Intermediate selectivity at $\mathbf{6 0} \mathrm{d}$}

AF neurons were selective in 60-d-old birds, which are still in the process of learning their song. The song and order selectivity for tutor song apparent at this age is not found in 30-d-old juveniles. This rapid change in selectivity provides another parallel between bird song learning and human speech learning. Human infants can initially discriminate between all phonemes tested (Eimas et al., 1987); by 6 months of age, linguistic experience has affected their phonetic perception, causing a narrowing of discrimination to those phonemes prevalent in the infant's native language (Kuhl et al., 1992).
The degree of selectivity for BOS at $60 \mathrm{~d}$ was still less than that of adults, however; cumulative distributions of $d^{\prime}$ values for song selectivity (specifically, $d^{\prime}$ BOS-ADULT CON and $d^{\prime}$ TUTOR-ADULT CON) at different ages show that $60 \mathrm{~d}$ values were intermediate to $30 \mathrm{~d}$ and adult values in both LMAN and $\mathrm{X}$ [Fig. 10A, $B$, respectively; $30 \mathrm{~d}$ and adult data from Doupe (1997) is reanalyzed here]. Sixty day neurons were also intermediate in their degree of order selectivity (data not shown); this was also evident when comparing average responses to forward, reverse, and reverse order stimuli at different ages. Figure $10 C$ shows that the average difference in LMAN responses between forward and reverse order stimuli at $60 \mathrm{~d}$ was less than that recorded in adults, implying that further selectivity for forward relative to reverse order stimuli will develop. 

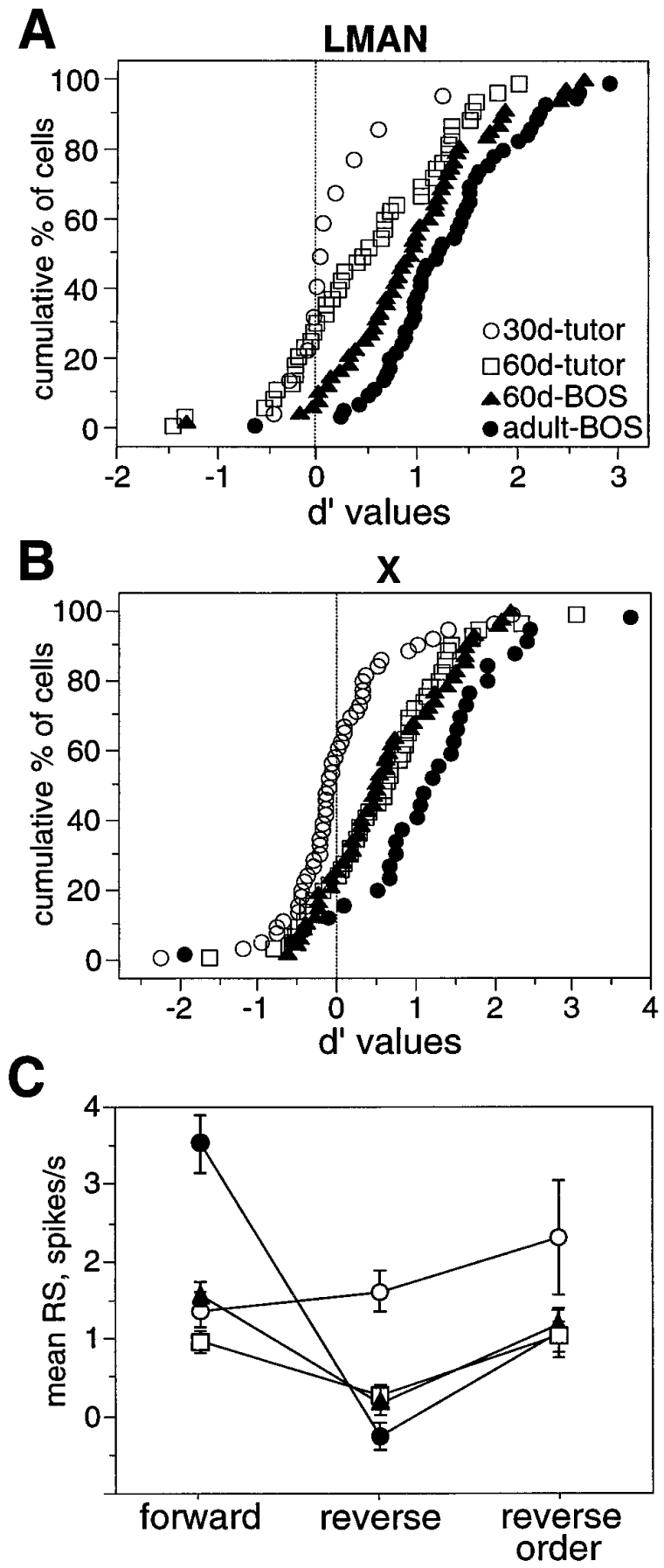

Figure 10. A comparison of selectivity at different ages. A, Cumulative distributions of $d^{\prime}$ values obtained from LMAN neurons at three stages of development. For $30 \mathrm{~d}$ neurons, $d^{\prime}{ }_{\text {TUTOR-ADULT CON }}$ values are shown as open circles. For $60 \mathrm{~d}$ neurons, open black squares denote $d^{\prime}$ TUTOR-ADULT

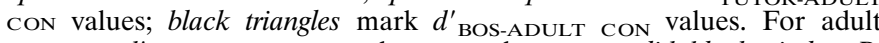

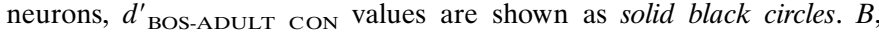
Cumulative distributions of $d^{\prime}$ values of $\mathrm{X}$ neurons from three stages of development. Symbols are as in $A$. $C$, A comparison of LMAN responses to forward, reverse, and reverse order song at three stages of song development. Open circles mark $30 \mathrm{~d}$ neuron responses to order permutations of tutor song; $60 \mathrm{~d}$ responses to these variations of tutor song and BOS are marked with open squares and black triangles, respectively. For adult neurons, black circles denote responses to permutations of BOS. The mean RS to each stimulus is shown. Error bars represent SEM.
Thus, neurons seem initially sensitive to local temporal order within a syllable and only later distinguish the global order of syllables within the song. This differential time course suggests that distinct mechanisms, differing in temporal integration times, generate these two kinds of order selectivity. Moreover, this sequence of order selectivity acquisition is analogous to sensory learning in zebra finches: juveniles memorize individual syllables first and their sequence later (Immelmann, 1969).

The presence of song and order selectivity by $60 \mathrm{~d}$ in LMAN and $\mathrm{X}$ is consistent with a role for selectivity during song learning, but what this specific function is remains unclear. In other systems, selective neurons subserve perceptual discriminations (Newsome et al., 1990; Riquimaroux et al., 1991). Similarly, song and order selective neurons may permit young birds to discriminate their own song from other auditory stimuli or may evaluate and guide developing song behavior.

\section{Selectivity differences between LMAN and $X$}

LMAN and $\mathrm{X}$ shared equivalent degrees of selectivity when mean $d^{\prime}$ values for different selectivity categories were compared (Fig. 8C); however, there was a trend for LMAN to be more selective than $\mathrm{X}$ when comparing mean SI. The difference between these two measures reflects the greater variance in LMAN responses relative to $\mathrm{X}$ responses; the greater difference in $\mathrm{RS}$ between preferred and nonpreferred stimuli in LMAN than in X (as detected by SI) was minimized in the $d^{\prime}$ measure, which is normalized by response variance. Whether SI measures of selectivity are physiologically relevant depends on the decoding capabilities of neurons downstream of LMAN or X. If downstream neurons average activity from many LMAN or X cells, then the difference in selectivity between the two nuclei as measured by SI could be important, and selectivity might increase as one progresses from $\mathrm{X}$ to LMAN. Alternatively, if downstream neurons are sensitive to the variance of individual LMAN or $\mathrm{X}$ responses, then $d^{\prime}$ values would be more appropriate selectivity measures. In this situation, the similarity of LMAN and $\mathrm{X} d^{\prime}$ values suggests that the same information would be available from LMAN and X responses.

\section{Potential mechanisms behind selectivity development}

Selectivity development in the AF is likely to reflect changes occurring within the AF as well as in its input nucleus, HVc. Although $\mathrm{HVc}$ in $60 \mathrm{~d}$ finches has not been characterized, adult $\mathrm{HVc}$ neurons are also song and order selective (Margoliash, 1983, 1986; Margoliash and Fortune, 1992; Lewicki and Arthur, 1996; Volman 1996). Furthermore, this selectivity develops during sensorimotor learning in white-crowned sparrows (Volman, 1993). Although the selective properties of $\mathrm{HVc}$ inputs could underlie AF selectivity, the differences between LMAN and $\mathrm{X}$ suggest that changes within the AF could also contribute to AF selectivity. For example, more LMAN neurons were inhibited to nonpreferred stimuli than were $\mathrm{X}$ neurons in both $60 \mathrm{~d}$ and adult zebra finches (Doupe, 1997). This indicates the presence of additional inhibitory circuitry within or between AF nuclei.

Increases in selectivity during development could be created by increasing responses to preferred stimuli and/or decreasing responses to nonpreferred stimuli. Which of these occurs might be determined by comparing the mean RS of neurons with these stimuli at different ages; however, interpreting the data available for this comparison is limited by the fact that 30 and $60 \mathrm{~d}$ and adult data have been collected in different experiments and thus in potentially varied conditions. Nonetheless, with this caveat in mind, 

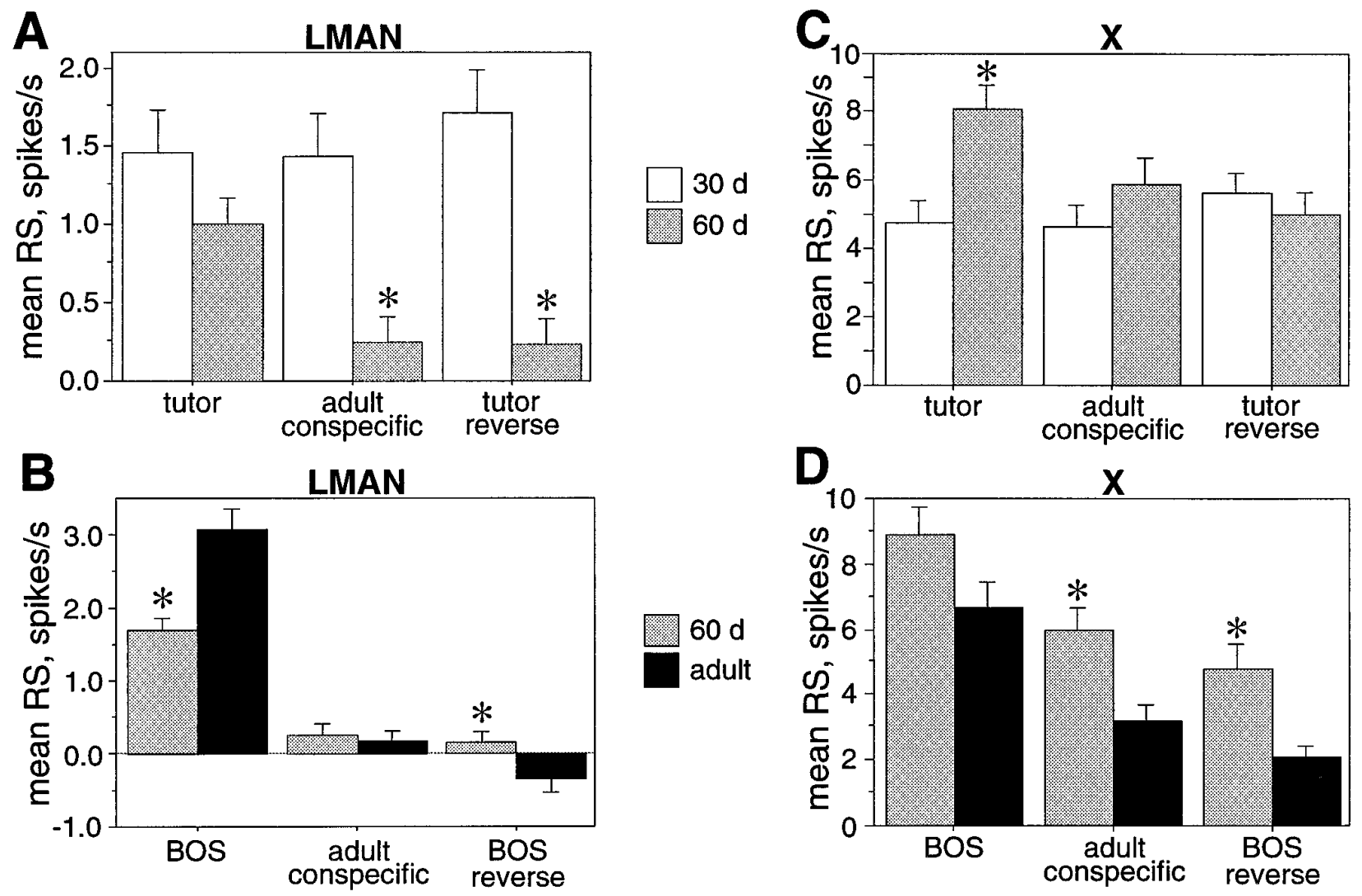

Figure 11. Comparisons of RS at different ages. A, Histograms of mean RS to tutor, adult conspecific, and reverse tutor song stimuli from LMAN neurons at $30 \mathrm{~d}$ (white bars) and $60 \mathrm{~d}$ ( gray bars). B. Histograms of mean RS of LMAN neurons compare $60 \mathrm{~d}$ (gray bars) with adult (black bars) responses elicited by BOS, adult conspecific song, and reverse BOS. Error bars indicate SEM, and asterisks identify significant differences between the ages $(p<$ 0.05 , unpaired $t$ tests). $C$, $D$, Same as $A, B$ respectively, but for $\mathrm{X}$ neurons.

comparisons of mean RS between different ages can point to possible events underlying selectivity development. For LMAN, comparisons of $30 \mathrm{~d}$ with adult data (Doupe, 1997) (Fig. 1A) suggest that both increased responses to preferred stimuli and decreased responses to nonpreferred stimuli produce selectivity. At the intermediate age of $60 \mathrm{~d}$, however, selectivity seemed primarily attributable to reduced responses to nonpreferred stimuli relative to $30 \mathrm{~d}$ responses (Fig. 11A); in fact, $60 \mathrm{~d}$ responses to nonpreferred stimuli already approximated adult responses (Fig. $11 B$ ). In contrast, $60 \mathrm{~d}$ responses to tutor song were not significantly different from those at $30 \mathrm{~d}$. Responses to BOS at $60 \mathrm{~d}$ also did not differ significantly from $30 \mathrm{~d}$ responses to all song stimuli (ANOVA, $\left.F_{(3,92)}=0.349 ; p<0.7898\right)$ and were substantially less than the BOS responses of adult neurons. In contrast, $\mathrm{X}$ neuron selectivity at $60 \mathrm{~d}$ might be attributable to increased responses to preferred stimuli relative to $30 \mathrm{~d}$ responses (Fig. 11C). Between $60 \mathrm{~d}$ and adulthood, responses to nonpreferred stimuli may well decrease, thus augmenting the selectivity of X neurons (Fig. 11D).

Although this study does not resolve the site of plasticity, several cellular events have occurred in LMAN and X by $60 \mathrm{~d}$ that could subserve the development of selectivity. In LMAN, NMDA receptors (Aamodt et al., 1992; Carrillo and Doupe, 1995), spine densities (Nixdorf-Bergweiler et al., 1995), synapse number (Nixdorf-Bergweiler, 1995), and DLM arborization density (Johnson and Bottjer, 1992) all decrease between $35 \mathrm{~d}$ and adulthood; this suggests that an initial reduction of connections could increase selectivity of a postsynaptic cell, perhaps followed by synaptic strengthening and/or growth of other inputs. A sim- ilar sequence occurs during the development of ocular dominance in the visual cortex (Antonini and Stryker, 1993). In X, the number of interneurons increases by $\sim 50 \%$ between 20 and $55 \mathrm{~d}$ (Nordeen and Nordeen, 1988; Sohrabji et al., 1993). Also, tyrosine hydroxylase and catecholamine staining in $\mathrm{X}$ has increased to nearly adult levels by $60 \mathrm{~d}$ (Soha et al., 1996).

\section{Song experience responsible for selectivity}

This study begins to address the nature of the experience involved in generating $60 \mathrm{~d}$ selectivity. Because of their importance to song learning, acoustic experiences of BOS and tutor song are likely candidates. Neurons shaped by either song experience should display a sensitivity to temporal and spectral features of that song. Neurons shaped by BOS experience could provide feedback to premotor targets of the AF about what the bird is singing. Neurons shaped by tutor song might act as a template; they could provide information about how well a bird's vocalizations match its memorized song model.

Several results here indicate that BOS experience is important for AF selectivity. Despite the immature quality of plastic song, neurons were sensitive to its complex properties; they had significant song and order selectivity for BOS, even when compared with the plastic songs of other juveniles. Also, neurons with strong preferences for BOS over tutor song predominated in both LMAN and X. This is consistent with a previous study in whitecrowned sparrows showing that selectivity in $\mathrm{HVc}$ is attributable to BOS experience (Volman, 1993). If the selectivity of the AF pathway is derived completely from such BOS-tuned $\mathrm{HVc}$ neu- 
rons, then LMAN and X neurons would likewise be tuned by BOS experience. Such neurons might be useful during song learning for identifying the current state of BOS, which would then be evaluated and changed accordingly; in adulthood birds might rely on BOS selective neurons for conspecific recognition (Margoliash, 1986).

If BOS experience alone generates the selectivity of AF neurons, then those neurons with equal responses to BOS and tutor song, as well as the selectivity for tutor song found here, could be explained by acoustic similarity between BOS and tutor song. This idea is consistent with the observation that an adult whitecrowned sparrow with equivalent $\mathrm{HVc}$ responses to BOS and tutor song also had a song very similar to its tutor (Margoliash, 1983). Furthermore, neurons with strong BOS preferences came from birds with songs least resembling the tutor in both adult (Margoliash, 1983) and juvenile (Volman, 1993) white-crowned sparrows, as well as in 60-d-old zebra finches (Fig. 9B). However, results from the similarity song test in the present study indicate that neurons with equal responses to BOS and tutor song were not always associated with acoustic similarity between these songs; some of these neurons came from birds with songs that had little similarity to the tutor song (Fig. 9B). Whether acoustic similarity accounts for neurons with equal responses to BOS and tutor song, as well as for the selectivity for tutor song, could be clarified experimentally with birds induced to sing abnormal songs by manipulating the syrinx early in development. Such birds' plastic songs would be extremely different from the tutor song. If they lacked neurons that responded equally to both stimuli, as well as song and order selectivity for tutor song, then acoustic similarity is a likely cause of these properties in normal birds.

Alternatively, the selectivity for both BOS and tutor song as well as the frequency of neurons with equal responses to BOS and tutor song could reflect the contributions of both songs to AF selectivity. Although HVc is shaped by BOS experience in whitecrowned sparrows, it is possible for the AF to derive its selectivity separately from the BOS-tuned neurons described in HVc. HVc has two populations of projection neurons (Sohrabji et al., 1989), which have not been both identified and examined in detail in physiological experiments; hence, X-projecting neurons could develop selectivity separately from RA-projecting neurons. Also, the BOS preference of HVc neurons was determined from multiunit recordings; such studies can potentially miss other kinds of selective cells if they are few or may ascribe a single quality to a recording site that actually comprises neurons with heterogeneous preferences. Finally, selectivity could be generated independently through the circuitry within the AF pathway. Thus, AF selectivity may not be fully explained by the BOS tuning described for HVc. If both BOS and tutor song experience contribute to AF selectivity, they could exert their respective influences simultaneously or sequentially; in the latter case, neurons with equal responses to BOS and tutor song could be making a transition from tuning for one song to another. An analogous shift in tuning has been characterized in the optic tectum of the barn owl. When the visual field of an owl is displaced horizontally with prismatic spectacles, the interaural time difference (ITD) selectivity of neurons shifts to an ITD that corresponds to the displaced visual field. As selectivity changes, multiunit sites pass through a transition state in which both the normal and shifted ITDs elicit equivalent responses (Brainard and Knudsen, 1995).

Finally, LMAN and X neurons that preferred tutor song over BOS are also inconsistent with an exclusive contribution of BOS experience to selectivity. Such tutor-preferring neurons were unlikely to have resulted from an inappropriate choice of plastic song as the BOS stimulus; song analysis showed that these neurons came from birds with the most mature songs, making song selection straightforward. These neurons were not as numerous as BOS-preferring neurons, however. Their lower number was unlikely to be attributable to presentation of the wrong tutor song; juveniles shared their cage with the tutor and were visually isolated from other adult male birds in the colony, which should have restricted their learning to the tutor in their own cage (Immelmann, 1969; Eales, 1987, 1989; Williams, 1990). Similarly, songs that did not resemble the tutor song in this study were also poorly stereotyped, indicating that these songs were immature, rather than the result of copying from a conspecific different from the tutor. If tutor song experience contributes to the selectivity of these neurons, the AF could store important information about the tutor song. A neural representation of a memorized tutor song, or template, is hypothesized to guide song learning (Konishi, 1965; Immelmann, 1969), and it is expected that by $60 \mathrm{~d}$, juveniles have acquired this template (Eales, 1985, Böhner, 1990).

Neurons with strong BOS preferences are not necessarily the product of BOS experience, because it is never known exactly what the bird has stored as a template: the only assay of this at present is what the bird eventually sings. For example, if a bird mismemorizes the tutor song and produces a perfect copy of its inaccurate template, then BOS itself could be a closer approximation of the template than the tutor song. This should result in a negative correlation between similarity to the tutor and strength of BOS preference; such a correlation occurred in this study (Fig. $9 B$ ). To confirm the role of BOS experience in shaping BOSpreferring neurons, it would be informative to study birds induced to sing abnormal songs. If BOS-preferring neurons existed in such birds, they would be more likely attributable to BOS experience rather than to a possibly inaccurate template. Whether tutor song also contributes to this selectivity could be revealed in studies of muted birds. Because these animals would not develop BOS, any observed selectivity would have to be attributable to tutor song experience.

The selectivity observed here in normal $60 \mathrm{~d}$ birds demonstrates the rapid and marked changes that occur in the AF during learning. Moreover, investigation of these neurons with BOS and tutor song stimuli revealed that both types of song experience may influence the properties of single neurons in this circuit. It remains to be determined whether and how this auditory selectivity contributes to the process of sensorimotor learning occurring at this age.

\section{REFERENCES}

Aamodt S, Kozlowski M, Nordeen E, Nordeen K (1992) Distribution and developmental change in [3-H]MK-801 binding within zebra finch song nuclei. J Neurobiol 23:997-1005.

Antonini A, Stryker MP (1993) Rapid remodeling of axonal arbors in the visual cortex. Science 260:1819-1821.

Böhner J (1990) Early acquisition of song in the zebra finch, Taeniopygia guttata. Anim Behav 39:369-374.

Bottjer SW, Miesner EA, Arnold AP (1984) Forebrain lesions disrupt development but not maintenance of song in passerine birds. Science 224:901-903.

Brainard MS, Knudsen EI (1995) Dynamics of visually guided auditory plasticity in the optic tectum of the barn owl. J Neurophysiol 73:595-614.

Carrillo G, Doupe AJ (1995) Developmental studies of glutamate receptor and peptide immunoreactivity in the zebra finch song system. Soc Neurosci Abstr 21:960.

Doupe AJ (1997) Song- and order-selective neurons in the songbird 
anterior forebrain and their emergence during vocal development. J Neurosci 17:1147-1167.

Doupe AJ, Konishi M (1991) Song-selective auditory circuits in the vocal control system of the zebra finch. Proc Natl Acad Sci USA 88:11339-11343.

Eales LA (1985) Song learning in zebra finches: some effects of song model availability on what is learnt and when. Anim Behav 33:1293-1300.

Eales LA (1987) Do zebra finch males that have been raised by another species still tend to select a conspecific song tutor? Anim Behav 35:1347-1355.

Eales LA (1989) The influences of visual and vocal interaction on song learning in zebra finches. Anim Behav 37:507-520.

Eimas PD, Miller JL, Jusczyk PW (1987) On infant speech perception and the acquisition of language. In: Categorical perception: the groundwork of cognition (Harnad S, ed), pp 161-195. New York: Cambridge UP.

Fortune ES, Margoliash D (1995) Parallel pathways and convergence onto $\mathrm{HVc}$ and adjacent neostriatum of adult zebra finches (Taeniopygia guttata). J Comp Neurol 360:413-441.

Green DM, Swets JA (1966) Signal detection theory and psychophysics. New York: Wiley.

Immelmann K (1969) Song development in the zebra finch and other estrildid finches. In: Bird vocalizations (Hinde RA, ed), pp 61-74. London: Cambridge UP.

Johnson F, Bottjer SW (1992) Growth and regression of thalamic efferents in the song- control system of male zebra finches. J Comp Neurol 326:442-450.

Konishi M (1965) The role of auditory feedback in the control of vocalization in the white-crowned sparrow. Z Tierpsychol 22:770-783.

Kuhl PK, Williams KA, Lacerda F, Stevens KN, Lindblom B (1992) Linguistic experience alters phonetic perception in infants by 6 months of age. Science 255:606-608.

Lewicki MS (1994) Bayesian modelling and classification of neural signals. Neural Comput 6:1005-1030.

Lewicki MS, Arthur BJ (1996) Hierarchical organization of auditory temporal context sensitivity. J Neurosci 16:6987-6998.

Margoliash D (1983) Acoustic parameters underlying the responses of song-specific neurons in the white-crowned sparrow. J Neurosci 3:1039-1057.

Margoliash D (1986) Preference for autogenous song by auditory neurons in a song system nucleus of the white-crowned sparrow. J Neurosci 6:1643-1661.

Margoliash D, Fortune ES (1992) Temporal and harmonic combinationsensitive neurons in the zebra finch's HVc. J Neurosci 12:4309-4326.

Newsome WT, Britten KH, Salzman CD, Movshon JA (1990) Neuronal mechanisms of motion perception. Cold Spring Harb Symp Quant Biol 55:697-705.

Nixdorf-Bergweiler BE (1995) The establishment of sex differences in the lateral magnocellular nucleus of the anterior neostriatum (LMAN) of the zebra finch is multifaceted. In: Nervous systems and behavior: proceedings of the 4th International Congress of Neuroethology (Burrows M, Matheson T, Newland PL, Schuppe H, eds), p 332. Cambridge, England: Thieme.

Nixdorf-Bergweiler BE, Wallhausser-Franke E, DeVoogd TJ (1995) Regressive development in neuronal structure during song learning in birds. J Neurobiol 27:204-215.

Nordeen EJ, Nordeen KW (1988) Sex and regional differences in the incorporation of neurons born during song learning in zebra finches. J Neurosci 8:2869-2874.

Nottebohm F, Stokes TM, Leonard CM (1976) Central control of song in the canary, Serinus canarius. J Comp Neurol 165:457-486.

Price PH (1979) Developmental determinants of structure in zebra finch song. J Comp Physiol [A] 93:260-277.

Rauschecker JP, Tian B, Hauser M (1995) Processing of complex sounds in the macaque nonprimary auditory cortex. Science 268:111-114.

Riquimaroux H, Gaioni S, Suga N (1991) Cortical computational maps control auditory perception. Science 251:565-568.

Scharff C, Nottebohm F (1991) A comparative study of the behavioral deficits following lesions of the various parts of the zebra finch song system: implications for vocal learning. J Neurosci 11:2896-2913.

Soha JA, Shimizu T, Doupe AJ (1996) Development of the catecholaminergic innervation of the song system of the male zebra finch. J Neurobiol 29:473-489.

Sohrabji F, Nordeen KW, Nordeen EJ (1989) Projections of androgenaccumulating neurons in a nucleus controlling avian song. Brain Res 488:253-259.

Sohrabji F, Nordeen EJ, Nordeen KW (1990) Selective impairment of song learning following lesions of a forebrain nucleus in the juvenile zebra finch. Behav Neural Biol 53:51-63.

Sohrabji F, Nordeen EJ, Nordeen KW (1993) Characterization of neurons born and incorporated into a vocal control nucleus during avian song learning. Brain Res 620:335-338.

Sossinka R, Böhner J (1980) Song types in the zebra finch Poephila guttata castanotis. Z Tierpsychol 53:123-132.

Suga N, O’Neill WE, Manabe T (1978) Cortical neurons sensitive to combinations of information-bearing elements of biosonar signals in the mustache bat. Science 200:778-781.

Tolhurst DJ, Movshon JA, Dean AF (1983) The statistical reliability of signals in single neurons in cat and monkey visual cortex. Vision Res 23:775-785.

Volman SF (1993) Development of neural selectivity for birdsong during vocal learning. J Neurosci 13:4737-4747.

Volman SF (1996) Quantitative assessment of song-selectivity in the zebra finch "high vocal center." J Comp Physiol [A] 178:849-862.

Wang X, Merzenich MM, Beitel R, Schreiner C (1995) Representation of a species-specific vocalization in the primary auditory cortex of the common marmoset: temporal and spectral characteristics. J Neurophysiol 74:2685-2706.

Williams H (1990) Models for song learning in the zebra finch: fathers or others?. Anim Behav 39:745-757. 